\title{
Under What Conditions Are Students Willing to Protest? \\ Selective Incentives, Production Functions, and Grievances ${ }^{1}$
}

\author{
Ross L. Matsueda \\ University of Washington \\ Blaine G. Robbins \\ New York University Abu Dhabi
}

Steven J. Pfaff

University of Washington

October $28^{\text {th }}, 2020$

Word Count: 23,123

Key words: collective action, student protest, factorial survey experiment

Corresponding Author: Blaine G. Robbins, Division of Social Science, New York University

Abu Dhabi, United Arab Emirates, Email: bgr3@nyu.edu

\footnotetext{
${ }^{1}$ An earlier version of this paper was presented at the 2016 Annual Meetings of the American Sociological Association. This research was supported by grants from the University of Washington's Royalty Research Fund, the Blumstein-Jordan Endowed Professorship in Sociology, and the National Science Foundation (SES-1330559). Partial support for this research came from a Eunice Kennedy Shriver National Institute of Child Health and Human Development research infrastructure grant to the Center for Studies in Demography \& Ecology at the University of Washington (R24 HD042828). We thank Aimée Dechter, Maria Grigoryeva, Jerald Herting, Edgar Kiser, and Katherine Stovel for advice and recommendations, Richard Callahan for research and programming assistance, and participants of New York University’s workshop on The Future of Survey Experiments for comments and suggestions.
} 


\begin{abstract}
This article tests a theory of student protest based on collective action theories. Drawing on rational choice theories of selective incentives, critical mass theories of production functions, and social psychological theories of protest, the present article specifies a theory of willingness to protest. To test our model, we administer a factorial survey experiment of student protest to a random sample of undergraduate students. We find that both the perceived likelihood of a protest's success and one's intention to protest are affected by the magnitude of the grievance, selective rewards and punishments, and the number of participants. The latter effect suggests a decelerating production function. Finally, we find that the likelihood of success mediates much of the effect of social context on intention to protest, implying that actors consider the effects of incentives not only on their own behavior but also on the behavior of others.
\end{abstract}




\section{Under What Conditions Are Students Willing to Protest? \\ Selective Incentives, Production Functions, and Grievances}

\section{Introduction}

Student protests have been important examples of collective action and mass

mobilization. After several decades of relative calm, there has been a recent upsurge of protests on college campuses largely inspired by racial and ethnic injustice (Johnston 2015). At the same time, a dramatic rise in tuition and fees has created substantial changes in the demographic composition of students, the operation of colleges and universities, and the quality of student life. Rising tuition has become a salient issue for students at some public universities, leading to notable student protests against tuition increases. These events raise a puzzle for scholars of collective action: Under what conditions are students willing to protest?

Drawing on micro-level theories of collective action, this paper examines students’ willingness to protest tuition increases at a major public university. Recent sociological research on collective action has redrawn attention to micro-level processes, in part to provide a micro-foundation for resource mobilization theory (McCarthy and Zald 1977), the dominant theory of collective action through the 1980s (Klandermans 1984). Influenced by Mancur Olson's (1965) seminal theory of collective action, much of this work rejects a narrow view of rational choice in favor of a "thick” (Hechter and Kanazawa 1997) or “wide” (Opp 2009) version that assumes information is limited, rationality is bounded, and preferences are important conditions for action (Francisco 2010; Klandermans 1997; Medina 2007). This research expands upon the narrow utilitarian model in two principal ways: (1) by recognizing that potential protesters often influence each other, as emphasized by threshold models (Granovetter 1978) and theories of the critical mass (Marwell and Oliver 1993); and (2) by 
incorporating social psychological concepts associated with individual protest behavior, including grievances, selective incentives, collective action frames, perceived injustice, and political identities (Klandermans 1997; Opp 2009; van Zomeren et al. 2004).

We draw on this literature to specify a model of the conditions in which students are willing to protest against tuition increases. Our model combines person-centered explanations (based on individual differences in stable personalities and preferences) with situation-centered explanations (based on rational decision-making in situations). To test our model, we identified a population of undergraduate students at a major public university, drew a disproportionate random sample, and administered a factorial survey experiment. We find that both the perceived likelihood of a protest's success and one's intention to protest are affected by the magnitude of the grievance, selective rewards and punishments, and the number of participants. The latter effect suggests a decelerating production function. We also find that the likelihood of success mediates much of the effect of social context on intention to protest, implying that actors consider the effects of incentives not only on their own behavior but also on the behavior of others. Below, we review the literature on student protest, propose a theoretical model, discuss our research design, present the results, and review the implications of our findings in the discussion and conclusions.

\section{Student Protests as Collective Action}

The massive student movements and protests of the 1960s and 1970s—which included protests against the Viet Nam war, racism, and sexism-were not only important historicalpolitical events, but were also a source of rich data for exploring collective action and social movements. Strikes played a prominent role in student activism during the 1960s, perhaps most famously in the 1968 student protests and strike at Columbia University (DeGroot 2014). In subsequent decades, student protests remained a recurrent feature of American politics and 
continued to inspire research. In the 1980s, American campuses were the focal point of antiApartheid activism (Soule 1997). The Students against Sweatshops and the Fair Trade campaigns in the 1990s linked campus activism to the labor movement (Levi and Linton 2003). Notably, the AFL-CIO provided funds and professional support to Students against Sweatshops through Union Summer and other programs at many American campuses (Van Dyke et al. 2007).

Despite continuities in student protest across the decades (Van Dyke 1998), massive structural changes in higher education funding and affordability have not inspired commensurate levels of protest in the U.S. This is surprising given the growing material inequality in higher education, which has had important consequences for student life. In response to state legislators reducing financial support for public universities across the nation, administrators have steadily increased tuition and fees charged to students. In some states, support fell dramatically in response to the 2008 recession. Compared with pre-recession levels, state support declined by 54 percent in Illinois, 39 percent in Louisiana, 30 percent in New Mexico, 28 percent in Wisconsin, and by 20 percent in both North Carolina and Washington state (New York Times 11/6/16). Much of the shortfall in state funding was recuperated by increasing tuition and fees. Between 2000 and 2013, tuition grew at an average rate of more than 50 percent at American public research universities (College Board 2014). Increasingly, the burden of financing public higher education has disproportionately shifted to students and their families, leading many to take on crippling levels of student loan debt (Houle 2014).

Changes of this magnitude practically invite rebellion. Outside of the U.S., several massive protests led to reductions in tuition. For example, in 2010, responding to a proposed 100 percent increase in tuition, students at ten of eleven Puerto Rican campuses staged strikes of varying duration and intensity. In the fall of 2010, students in the United Kingdom engaged in 
national demonstrations and massive walk-outs as response to a government plan to triple tuition fees (Hensby 2017). The campaign, however, proved unsuccessful in producing a largescale national movement.

However, in Canada, when Quebec officials proposed a 75 percent increase in tuition and fees over a five-year period, 200,000 students—about half of the province's student body_joined a strike in the spring of 2012 that lasted for more than six months, crippling higher education. Consequently, the Liberal party passed a draconian bill (Bill 78) that stripped fundamental rights, such as the right to assembly. After months of student protest, the reigning Liberals_-previously expected to win the provincial election-were defeated, and the new government rescinded both the tuition increase and Bill 78 (Mehreen and Thomson 2017). Similarly, in South Africa, following successful student protests to “decolonize higher education”-including removing legacies of Apartheid and colonial symbols such as a statue of Cecil John Rhodes_-massive student protests from Cape Town to Johannesburg developed in the spring of 2015 in response to a threatened 10 to 12 percent increase in tuition. President Zuma responded by freezing tuition in late 2016. In 2017, a planned 8 percent increase in tuition led to a massive, and at times, violent student protests. ${ }^{2}$

In the U.S., student protests against tuition increases have occurred but mass participation has often been lacking. Public university students in California mobilized against program cuts and increases in tuition and fees — by as much as a two-fold increase-in the early 1990s. Around this time, students at multiple University of California campuses protested a 32 percent increase in tuition. Perhaps the broadest mobilization occurred at San Diego State

\footnotetext{
${ }^{2}$ For media coverage of some of these episodes, see "Student Protests Tie Up Campuses in Puerto Rico", New York Times, May 20, 2010; and “In Puerto Rico, Protests End Short Peace at University”, New York Times, February 17, 2011; “Quebec's students provide a lesson in protest politics: sustained action over tuition fees helped defeat Quebec's Liberal government”, The Guardian, September 7, 2012; and “The Student Protests Roiling South Africa”, The New Yorker, October 21, 2016.
} 
University. To accommodate a statewide budget crisis in 1990, San Diego State and other California state colleges announced vertical cuts in departments, elimination of faculty, and substantial increases in student tuition and fees. Students responded by organizing a petition drive that included 11,000 students (about a third of the student body), large-scale demonstrations, and a campus vigil that lasted six months. In an attempt to thwart the vigil, the administration used campus police to harass protesters, issued citations and arrests, and threatened students with prosecution for vagrancy (Wood 2014, pp. 269-277). Such efforts at control ultimately failed, and the administration scaled-back cuts to faculty and programs, abandoned vertical cuts, and reduced tuition increases.

More recently, in 2010, American student activists staged a "National Day of Action” in response to tuition increases and budget cuts across the United States. Protest nationwide was sporadic and involved relatively few students (Christian Science Monitor 3/4/2010). Subsequently, students from over 100 universities participated in the "Million Student March" in favor of free college tuition in the fall of 2015, but by the spring of 2016 the campaign had faltered and calls for protest elicited no more than a couple of dozen students at a handful of universities.

This brief overview of student activism suggests why the study of student protests offers distinct advantages for exploring theories of collective action (Hensby 2017). Unlike many other protest groups, college students constitute a clearly defined population, making representative sampling possible. Historically, students have constituted an alert and wellinformed population, engaging in protests over a variety of issues, ranging from global political issues to narrow parochial issues, such as local tuition increases (Andrews and Biggs 2006; Crossley 2008; Hirsch 1990; McCarthy et al. Forthcoming; Zhao 1998, 2000). Many college students are undergoing similar life-course transitions—-from living with parents to being on 
their own, from ending adolescence to beginning adulthood, and from completing education to preparing to enter the labor force. Therefore, they have readily discernable common interests and shared concerns about cost-effective education, career training, and student culture, as well as common obligations of attending classes, completing assignments, and working with other students. Finally, students have relatively observable resources, including finances, human capital, and social capital.

As examples ranging from the U.S. to Canada to South Africa and to Puerto Rico suggest, large-scale protest is a potentially effective way to roll back tuition increases. This raises an important question: Why are students willing to tolerate worsening material conditions, but at other times willing to protest against those conditions? To answer this question, we turn to theories of political protest and collective action.

\section{Micro-Level Theories of Collective Action and Protest}

Olson's Theory of Collective Action

Rational choice theories of collective action (Chwe 1999; Francisco 2010; Hardin 1982; Medina 2007; Oliver et al. 1985; Opp 2009) typically begin with Mancur Olson’s (1965) seminal work, The Logic of Collective Action. Logic presents a rational choice theory of collective action that is clear, concise, and compelling, but has also been subject to criticism from sociologists. For this reason, we begin by reviewing Olson’s theory, summarize sociological criticisms, review recent empirical studies of rational choice and extensions, and finally, present a "wide” sociological rational choice model that considers sociological research and findings.

Olson's (1965) theory of collective action begins with the assumption that individuals maximize utility subject to constraints. For Olson, collective action must overcome the freerider problem: rational actors will not contribute to the provision of a common good if they can 
consume it without incurring the costs of contributing. In relatively small groups, where faceto-face interaction reduces communication costs, group leaders or advocacy organizations can overcome the free-rider problem by providing selective incentives to contributors. "Pure" selective incentives for participation are provided up front and are not contingent on the success or failure of the collective action.

With respect to student protest, two competing sets of actors in the form of groups or organizations are likely to dole out selective incentives. One set of actors represent the college administration, which has an interest in discouraging protests that involve boycotting classes and otherwise disrupting college activities. Potential sanctions include losing credit for skipping class, lowering grades, and even expulsion (for historical examples of such tactics see McCormick 1990; DeGroot 1998). A second set of actors represent student groups—including, at times, external groups such as labor unions and advocacy organizations - that have an interest in encouraging as many students as possible to join the protest. Potential incentives include monetary subsidies and status-enhancing rewards.

For several reasons, Olson (1965) maintains that collective action is unlikely in relatively large groups such as students at a large university. First, individual contributions are not noticeable in large groups. Olson maintains that large groups decrease the extent to which an individual's contribution makes a difference (i.e., is efficacious) in the provision of a public good, which reduces the incentive for individuals to contribute. Second, although the individual costs of participation may be lower in large groups, those costs are offset by greater costs of communication and organization. Third, the individual utility of a public good in large groups may be lower because it must be shared by more individuals. These three mechanisms informed Olson’s (1965) most controversial proposition: “Indeed, unless the number of individuals in a group is quite small, or unless there is coercion or some other special device to make individuals 
act in their common interest, rational, self-interested individuals will not act to achieve their common or group interest (p. 2).” Social scientists have questioned this proposition empirically and have lodged critiques of Olson's paradigm. This is now where we turn.

\section{Sociological Criticisms of The Logic of Collective Action}

Certain elements of Olson's (1965) theory—such as selective incentives-have been integrated by sociologists into models of collective action (Klandermans 1984; Macy 1990; Marwell and Oliver 1993; Opp 1988). Other aspects of Olson’s theory, however, have been subject to consistent critique by sociologists, including Olson’s treatment of group size, grievances, non-material incentives, and independent decision-making.

Group size. Sociologists have criticized, on both theoretical and empirical grounds, Olson's argument that large groups exhibit a lower likelihood of collective action. Theoretically, alternative models suggest that certain abstract scope conditions delimit the negative relation between group size and collective action. Oliver and Marwell (1988), for instance, suggest that large groups undermine collective action only under conditions of rival consumption or zero jointness of supply (see also Hardin 1982; Opp 2009). Large groups, in contrast, promote collective action under conditions of pure jointness of supply or non-rival consumption (consumption by one individual does not diminish a good's availability to others). Empirically, studies find inconsistent evidence for the effects of group size on collective action: some studies show positive correlations, while others reveal negative associations (see Kollock 1998 for a review). Furthermore, the costs of communication are unlikely to be a prohibitive factor in organizing collective action (Ledyard 1995), particularly in the age of social media, and may be important only when production functions-the likelihood of securing the public good as a function of individual contributions - are accelerating (Oliver et al. 1985). Finally, the 
proposition that individual contributions in large groups are not noticeable is an empirical question.

Grievances. Sociologists have also criticized Olson for discounting the role of grievances (Bergstrand 2014; Pfaff and Hechter 2020; Hechter et al. 2016; Klandermans 1997). Olson argues that the intensity of grievances in small groups can be important incentives to participate in collective action. Grievances interact with personal efficacy: as individual contributions to collective action diminish, the effect of grievances declines. This implies that at the limit of zero efficacy, grievances cease to matter and fail to offset costs of contributing. Consequently, Olson discounts the role of grievances in large groups. This is consistent with many resource mobilization theories, which tend to disregard the causal role of grievances in macro-models of collective action (Oberschall 1973; Zald and McCarthy 1979). Social psychological research, however, finds that the magnitude of grievances increases the likelihood of collective action, presumably by increasing the incentive to protest. Suddenly-imposed grievances, such as tuition increases and violated principles held dear to actors, can be powerful mobilizers (van Zomeren et al. 2004; van Zomeren et al. 2008). Other sociologists argue that grievances — when shared across members of a population—heighten collective identification and increase the salience of group boundaries (McVeigh 2009; Pfaff 1996), which can spur collective action (see also Grasso and Giugni 2016). Likewise, as Gamson (1990) argues, grievances framed as unjust and unfair can be strong motivators for collective action for which a successful protest would eliminate the grievance and injustice (e.g., tuition increase).

Non-material incentives. In addition to group size and grievances, sociologists have criticized Olson for focusing exclusively on pecuniary incentives, while ignoring social and moral incentives (see Gamson 1990; Jenkins 1983; Willer 2009). To be fair, Olson (1965: 6061) includes nonpecuniary or "soft" incentives, such as social incentives (prestige, respect, and 
friendship), moral incentives, and internalized norms (violation of which produces shame or guilt) in his model, and argues that insofar as they are conceptualized as selective incentives, they may be important for collective action. Nevertheless, Olson dismisses nonpecuniary incentives as holding sway only in small groups and as being virtually unmeasurable (Opp 2009). We question both of these assumptions: nonpecuniary incentives are equally likely to hold in large groups as in small (Chwe 1999; Gould 1991; Kitts 2000; Sampson et al. 2005), and survey research has advanced in measuring soft incentives (Klandermans 1984; Opp 1988). Independent decision-making. Finally, sociologists have also criticized Olson (1965) for assuming that individuals make decisions independently of each other. Drawing on Schelling's (1971) theory of thresholds, Granovetter (1978) developed a decision-making model in which actors consider the total number of other participants when choosing to participate themselves (see also Centola and Macy 2007; Chwe 1999; Gould 1993; Kim and Bearman 1997; Lohmann 1994; Lopez-Pintado and Watts 2008; Macy 1991). Marwell and Oliver (1993) extended this model in their theory of the critical mass, which centers on the form of the production function (the marginal effect of the number of protesters on a protests' likelihood of success), group heterogeneity in interests, and group heterogeneity in resources as key exogenous variables. ${ }^{3}$ We follow this tradition, relax the assumption of independent decision-making, and assume that individuals make sequential decisions with knowledge of the total number of other participants. Empirical Research on Rational Choice Models of Collective Action

Sociologists in the rational actor tradition responded to the limitations of Olson's model by expanding their conception of rationality. Rejecting the "thin" conception dominant in Olson's microeconomics, they offered a Weberian understanding of motivation. Under the rubric of "thick" rationality, they asserted that the rational action model permitted people to act

\footnotetext{
${ }^{3}$ For research at the intersection of student protests and the critical mass, see Crosley and Ibrahim (2012).
} 
interdependently rather than independently. They are motivated by non-material preferences, beliefs, perceptions, norms, and social sanctions. Individuals are assumed to be other-regarding, imperfectly informed, socially constrained, and prone to satisficing rather than maximizing (Coleman 1990; Hechter and Kanazawa 1997; Opp 1999).

An important milestone in developing a sociological rational choice model of collective action was Klandermans’ (1984) specification and test of a micro-level value-expectancy theory. Drawing on Atkinson’s (1957) psychological value expectancy approach to explain motivation and aspiration, Klandermans' (1994) model of willingness to protest emphasized the expected probability of the consequences of joining a movement (e.g., probability of success) weighted by the value of the consequences (e.g., value of success). From this early work, Klandermans and others (Klandermans 1997; Klandermans et al. 2008; Van Stekelenburg and Klandermans 2010) have drawn upon value-expectancy theory and the social psychology of collective action to propose models of movement participation that include emotions, grievances, efficacy, identification, and embeddedness.

Perhaps the most systematic effort to explain the willingness to protest is Opp’s (2009) structural-cognitive model of collective action. Opp’s model is noteworthy for synthesizing mechanisms at the micro and macro levels. His model specifies how macro-level resources, opportunities, and mobilization strategies shape cognitive frames and incentives to protest at the micro level. To explain motivation, his model combines value-expectancy, social identity, and cognitive framing theory. It advances the literature by integrating macro-level explanations found in the social movement literature with micro-level factors specified by the social psychologists. These include not only material grievances but also perceived group success, subjective efficacy, norms and social sanctions. 
The empirical literature testing elements of this model is too extensive to review here, however, certain patterns of findings are evident. Whereas many studies find support for an association between perceived efficacy and willingness to protest (Jasso and Opp 1997; Finkel and Muller 1998; Finkel et al. 1989; Klandermans 1984; Muller et al. 1991), some elements of the structural-cognitive model have not been consistently supported. Grievances, social incentives, protest norms, and identity are sometimes positively associated with individual participation in collective action (Bergstrand 2014; Muller et al. 1991; Pfaff and Hechter 2020; Schussman and Soule 2005), but at other times not (e.g., Lim 2008; Opp 1989; Opp et al. 1996; Valdez 2011).

In spite of the extensiveness of the literature, there have been few experimental studies testing elements of the structural-cognitive model (Jasso and Opp 1997; Rasler 1996; Willer 2009), none of which have tested it in its entirety. Moreover, Opp (2009) underplays production functions in his theoretical model. This is understandable, given that the literature has neglected to observe production functions empirically, develop models that endogenize them, or identify mechanisms accounting for their indirect effects (see Robbins et al. 2020 for an exception). As Opp notes, “...systematic attempts at identifying production functions for different types of situations are so far missing (Opp 2009: 78).” We intend to resolve this omission by explicitly adding production functions into our theoretical model and by empirically tracing production functions in our statistical models.

\section{A Theory of Willingness to Protest}

To move beyond Olson’s theory, we need to understand how social context influences collective action either by interacting with individual propensities or by activating social mechanisms that enhance cooperation (Medina 2007). Conventionally, the incentives in utility functions derive from exogenous situational interventions beyond the control of the actor, which 
we hypothesize affect the actor's behavior by altering the costs and benefits of their behavior. In the case of political protests, the state commonly imposes interventions as do social movement organizations or interest groups. Our research design embeds such exogenous interventions into political protest scenarios, which constitute the social conditions for collective action.

In specifying these conditions, we build on sociological rational choice theory and social psychological models of collective action (Klandermans et al. 2008; Opp 2009; Van Zomeren et al. 2008). Subjective expected utility models focus on expected utility as perceived by the individual. They are rational models in that they assume the mean of the probability distribution of subjective expected utility falls on the population value of objective expected utility. We follow this tradition in specifying a subjective expected utility model of the willingness of students to protest.

\section{A Utility Function for Student Protest}

We begin with a rational choice model of an actor's willingness to participate in collective action (Oberschall 1980; Oliver et al. 1985). If we let $T(\theta)$ be the net payoff to an individual for an investment of size $\theta$, we can specify an equation for an individual's decision to participate in collective action:

$T(\theta)=V P(\theta)+S \theta-C \theta$

where $V$ is the expected gain (or value) from obtaining the public good (Olson 1965), $P(\theta)$ is the probability of obtaining the public good (i.e., likelihood of success) produced by an investment of size $\theta, S$ are selective incentives (in the Olsonian sense) for a contribution of size $\theta$ (which can be positive or negative), and $C$ are other costs for a contribution of size $\theta$ to the individual (such as time, effort, and opportunity costs). 
To find the value of $\theta$ that maximizes an individual's utility, we can differentiate eq. (1) with respect to $\theta$, set the derivative $N^{\prime}(\theta)$ equal to zero, and solve for the derivative of the production function $P^{\prime}(\theta)$ (see Oliver et al. 1985). This yields a decision rule, in which an individual will participate in collective action when

$V P^{\prime}(\theta)+S>C$

That is, when an individual's marginal contribution to success multiplied by the value of the good plus any selective incentives is greater than the cost of contributing, she will participate. Note that for Olson (1965), as group size increases, $P^{\prime}(\theta)$ approaches zero (i.e., becomes unnoticeable) and selective incentives are unable to offset the costs of contributing, which results in non-cooperation.

We can also express the returns of a contribution of $\theta$ units to the success of a collective action as follows:

$P^{\prime}(\theta)=\frac{C-S}{V}$

This suggests that when an individual's marginal contribution to success exceeds the ratio of costs (minus selective incentives) to the value of the public good, each unit contributed yields a profit. When the marginal contribution is less than this ratio, each unit contributed yields a loss.

Expected Gains. The expected gain, $V$, includes the expected reduction in tuition from the protest (i.e., the collective good), plus expected psychic returns from a successful protest. For example, among individuals who perceive the tuition increase as unjust, the expected reduction in injustice is a psychic return. Often a sense of injustice is induced by organizers aligning collective action frames to highlight the unfairness of tuition hikes.

As noted above, Olson (1965) and resource mobilization theorists tend to discount the role of grievances in collective action. We argue, instead, that grievances are a key incentive for 
initiating and sustaining collective action (Finkel et al. 1989; Klandermans et al. 2008; Medina 2007). Some research suggests that incidental, or "suddenly-imposed," grievances—such as a tuition increase-are more effective in mobilizing collective action than long-standing structural grievances (Pfaff and Hechter 2020; Hechter et al. 2016; Tausch et al. 2011). It follows that larger threatened tuition increases imply greater grievances and, therefore, higher potential gains from a successful protest.

Expected Likelihood of Success. We hypothesize that expected gains interact with the expected likelihood of success, $P(\theta)$, which is an important determinant of willingness to protest (Olson 1965; Klandermans 1984; Oliver and Marwell 1985). Self-regarding actors are unlikely to join a protest that is doomed to failure, unless mere participation brings sufficient reward — as in ritualistic displays of solidarity (Collins 2005). Thus, if potential participants expect a protest to succeed, they will be more likely to participate. We expect this relationship to be positive and monotonic. Expected success may lead to participation by increasing one’s perceived influence on the outcome_-as specified in eq. (1)—or perhaps by invoking a norm of participation (Opp 2009). Moreover, expected success, in turn, is a function of the number of participants who have joined the protest to that point, the degree of solidarity among protesters, and the individual's expected contribution and sense of efficacy in bringing about a successful protest.

Selective Incentives. Selective incentives, or tangible punishments and rewards given for contributing to or refraining from collective action, are at the heart of any expected utility theory of collective action. Most scholars of collective action agree that selective incentives, modeled as $S$ in our equations, are sufficient conditions for overcoming the free-rider problem (Olson 1965; Oliver 1980). Typically, selective incentives are administered instrumentally by an organization—such as a governmental authority or advocacy group — that threatens protesters 
with punishment for participation in collective action. In our example, a university administration might threaten would-be student protesters with academic sanctions for participating, while pro-student organizations, such as a sponsoring labor union, may provide pecuniary rewards for participating.

A strong test of the theory of selective incentives must address two distinct empirical questions. First, do the selective incentives typically used in the past have an effect on collective action? Second, if the answer is “no,” a further question is whether stronger incentives — which we could imagine being used under future institutional configurations — have an effect? This can be a crucial counterfactual question relevant for understanding the effects of selective incentives: How strong and draconian must selective disincentives (incentives) become to deter (motivate) student protest? It could be that a theory of student protest based on selective incentives is accurate but the disincentives must be so severe that, under current institutional safeguards for individual rights, they are infeasible, particularly given likely negative externalities (Byman 2016). The factorial survey design allows us to consider such counterfactual conditions. A lower grade given by a university administration, for instance, may have little effect on willingness to protest, but expulsion-which may be impractical to administer due to norms of fairness—might have a strong effect.

Social Incentives. Following sociologists’ criticisms of Olson (1965), we also model social and moral incentives. For example, participation in the protest could bring status, respect, and a positive reputation among their peers at a time in the life course when youth are preoccupied with peer status (Willer 2009). Such an effect could be intensified when peers actively recruit individuals to the cause (Chong 1991; Schussman and Soule 2005; Snow et al. 1980). We will embed status, respect, and peer approval as key social incentives in our vignettes. Each of these operates in $S$ as selective social incentives. 
Frames. Organizers can frame grievances in a number of ways. Political actors often act as signifying agents, who actively “produce, maintain, and fight for meanings” they find important and "struggle to have certain meanings and understandings gain ascendance over others” (Snow and Oliver 1995: 587). Collective action frames are ways of characterizing a situation that is likely to mobilize others to participate. Members of political organizations often intentionally manipulate frames to maximize the number of participants by aligning collective action frames with the interests of potential constituencies (Snow et al. 1986). Gamson (1990) argued that successful frames are those that define the problem and solution in collective terms, define antagonists as "them” in opposition to “us," and define an injustice that collective action can correct. From a narrow rational choice perspective, these are forms of information actors use to make decisions. For student protest, we embed three pieces of information in the protest scenario that could produce effective frames: (1) collective efficacy (e.g., walk outs at other universities have succeeded in reducing tuition), which increases the expected likelihood of success of the protest, $P$; (2) injustice (e.g., top administrators are planning a salary increase), which increases the expected gains, $V$, from protest; and, (3) solidarity (e.g., the student group declares that all should unite against social injustice), which increases the expected likelihood of success of the protest, $P .^{4}$

Costs. Our utility function distinguishes between costs of participation, $C$, from selective disincentives, $S$. Costs of participation, $C$, like selective disincentives, are contingent upon participation and include costs associated with lost time, energy, and opportunities. But unlike

\footnotetext{
${ }^{4}$ Our research design has the strength of manipulating the situation of protest-varying key contextual dimensions like expected gains, expected rewards and costs of protesting-but the weakness of being unable to model dynamics of collective action as it unfolds over time. Thus, we are unable to examine dynamic mechanisms by which political leaders align frames to appeal to broad constituencies (e.g., Snow et al. 1986).
} 
selective disincentives, organizations do not selectively administer $C$ to participants (and we do not manipulate $C$ in our experimental design).

Interdependence, Number of Participants, and Production Functions

Although our research design does not allow us to model explicit dynamics of collective action over time, we can examine static hypotheses derived from a dynamic model of interdependent actors. Granovetter’s (1978) threshold model posited that individuals, when making the decision to join a protest, would consider the total number of protesters who have joined up to that point. Granovetter showed that if potential protesters have different thresholds for protesting based on the cumulative number of joiners, an individual's decision depends on the distribution of thresholds in the population at risk. Oliver et al. (1985) extended this work by specifying a theory of the critical mass, exploring the implications of different production functions, using simulation methods, and examining the effects of heterogeneity of resources in populations at risk of collective action. We build on this work by specifying a model of interdependence and by estimating a production function empirically. ${ }^{5}$

Oliver et al. (1985, p. 523) define a production function as relating “contributions of resources to changes in the level of the collective good.” ${ }^{6}$ Resources include time, money, effort, and other contributions, and the level of the collective good includes the "probability, extent, and effectiveness of group actions in pursuit of collective goods” (emphasis added) (Oliver et al. 1985: 523). The critical variable here is the aggregate cumulative effect of

\footnotetext{
${ }^{5}$ This approach requires four assumptions (Oliver et al. 1985): (1) individual decision-making is sequential and not simultaneous; (2) often a small proportion of the population-a critical mass-makes substantial contributions to collective action, while the remaining population does little or nothing; (3) in making their own decisions to participate, individuals are interdependent and consider how much others have already contributed; and, (4) individuals have full information about the production function's form.

${ }^{6}$ The concept of a production function, of course, is taken from neoclassical economics and describes processes of production by relating inputs (factors of production) to economic outputs (goods), and can be used to derive the marginal product for each factor of production. By analogy, we are modeling the production of a public good (successful protest) and deriving the marginal contribution of individual protesters.
} 
resources contributed to collective action, which traces out the production function. In our example of student protest, the resources invested are a student's time and energy. To simplify matters, we treat students as interchangeable and define resources as a student's participation in the protest. We can graph the production function by plotting the probability that the protest will secure the public good (tuition reduction) by the cumulative resources (number of students) contributed. Oliver et al. (1985) show how the shape of the production function can have important consequences for collective action (Heckathorn 1996; Kollock 1998; Oberschall 1994). Figure 1 presents the shapes of three common production functions.

Most economic theories assume an S-shaped curve (Panel A) in which the initial payoff for participation is small, resulting in steep startup costs. High payoffs follow for contributions in the middle of the distribution. Finally, at the end of the distribution, late joiners face diminishing returns to contributions as a sufficient "critical mass" of participants produces near certainty of success, which, in turn, creates free-rider problems later on.

\section{[Figure 1 about here]}

A special case of the S-shaped curve is an accelerating production function, in which increasing marginal returns magnify successive contributions (Panel B). In this case, interdependence is positive and free-riding is not a problem because early contributions make later contributions increasingly attractive, creating a potential explosion in participation later on. The challenge here is to elicit initial contributions. This can be accomplished by coordinating and organizing individuals using an all-or-none contract or a social norm: If members with only moderate interests or resources are convinced that everyone should contribute because it is in everyone's interest to do so, the protest is likely to succeed, and indeed, likely to explode (Hardin 1982; Macy 1990; Oliver et al. 1985). 
Finally, Panel C depicts a decelerating production function, in which decreasing marginal returns dampen successive contributions. Here, interdependence is negative and freeriding is a problem. Whereas first movers enjoy high marginal returns, subsequent joiners reap low marginal returns. Because individuals with the greatest interest are likely to contribute first, late movers are increasingly likely to free-ride, resulting in inefficiency and underinvestment. ${ }^{7}$

We contribute to this literature by empirically estimating aggregate production functions using a factorial survey design. We define aggregate cumulative resources invested as the total cumulative resources $\theta_{C}$ previously invested by all other individuals up to that point. We simplify resources by assuming each individual contributes one unit of resources to obtaining the common good, and treat cumulative number of participants $C N$ as a manipulated vignette dimension in our factorial survey experiment. It follows that the protest's likelihood of success per contributing individual traces out an aggregate production function, $P(\theta)$, which expresses the marginal effect of an individual contribution on the probability the protest will succeed at the point in which $C N$ other individuals have contributed (Centola 2013; Oberschall 1980; Oliver et al. 1985). That is, the marginal return to an individual's investment will vary by how many others have joined up to that point. By eliciting individual subjective probabilities of the likelihood of success while varying the number of cumulative contributors, we can aggregate the results to obtain an estimate of the population production function. Note that we are making a simplifying assumption that an individual's willingness to protest is a function only of the cumulative number of protesters to that point, and not a function of the individual's expectation of changes in others' future behavior that may result from the individual joining the protest.

\footnotetext{
${ }^{7}$ Oliver et al. (1985) find in their simulations that heterogeneity of resources and interests are important for accelerating production functions, but only heterogeneity of interests matter for decelerating production functions.
} 


\section{Individual Predispositions and Stable Preferences}

Research shows that individual-level factors do foster participation in collective action, leading Snow and Oliver (1995, p. 578) to conclude that "there is something to be gained by reconsidering 'personality.'” From a rational choice perspective, these stable characteristics constitute an important component of preferences and can be incorporated into a wide version of rational choice. Such preferences may directly affect participation as well as moderate the effects of situational incentives (Simpson and Willer 2008).

For example, previous participation in political protest may increase the probability of future protest by influencing the salience of social and political identities, the expected success of protests, and attitudes and expectations about politics and protest behavior (Fillieule 2012; Klandermans et al. 2008; Van Zomeren et al. 2008). Social identities are categories used by individuals to evaluate and distinguish themselves from other individuals, collectivities, and groups (Polletta and Jasper 2001). Once individuals come to identify with a salient social category, such as "student," they will exhibit preferences for behaviors that align with corresponding role identities (Stets and Burke 2000) and act in ways to benefit in-group members (Tajfel 1981). Moreover, Akerloff and Kranston (2000) include identity in a utility function to explain behavior, showing that a "student activist" identity, for instance, may increase protest behavior by enhancing one’s self-image.

Research also finds that self-efficacy increases the likelihood of participation by increasing energy and social skills (Klandermans et al. 2008; Werner 1978). Furthermore, collective action may be more likely among individuals who follow a cooperative social value orientation versus an individualist or competitive orientation (Van Lange 1999; Simpson 2004). Participation may also be more likely when individuals hold favorable attitudes toward protesting, such as a protest is justified and warranted even if it may fail (Opp et al. 1996). 
Finally, given that political protests are typically risky behaviors, individuals with propensities for risk taking should be more likely to participate in collective action than the risk averse (Francisco 2010; Lichbach 1995).

\section{Factorial Survey Experiment, Sample, and Measures}

Factorial Survey Experiment

To test our theory of the conditions in which students are willing to protest, we use a factorial survey experiment (FSE; Hinz and Auspurg 2014; Jasso 2006; Rossi and Nock 1982). ${ }^{8}$ The FSE approach presents respondents with hypothetical protest scenarios in narrative form. Embedded in the narratives are dimensions and levels. Vignette dimensions characterize different aspects of the social context, such as grievances and the number of participants, that affect willingness to protest (see Appendix A). Vignette levels are the values of the vignette dimensions (e.g., 10 protestors versus 10000 protestors) used to elicit judgments, decisions, and or behavioral intentions from respondents. We thus experimentally manipulate different aspects of the conditions in which protests occur (dimensions) by randomly assigning attribute values of those conditions (levels) to protest scenarios; conditions that-in reality-external organizations manipulate (e.g., university administrations and student political groups). In terms of estimation, vignette dimensions are the independent variables in our statistical models that vary according to the values of the vignette levels. For each vignette, subjects were asked whether they believe the depicted protest would succeed and whether they would participate in the protest. Likelihood of success and intention to protest are dependent variables in our statistical models, and correspond exactly to the outcomes specified by our theory.

\footnotetext{
${ }^{8}$ An alternative to vignettes is a conjoint experiment, in which characteristics are not embedded in scenarios, but rather merely presented in list form. We use a vignette method because we are trying to mimic a protest situation using a narrative (see Appendix A for a discussion).
} 
Each respondent assessed ten vignettes. We randomly assigned values of vignette dimensions to vignettes, which ensures that independent variables are uncorrelated. We also randomly assigned vignettes to respondents, which ensures that vignette dimensions are uncorrelated with respondent characteristics. The result is a pooled person-vignette data set generated from two sampling processes: a random sample of undergraduates from the population of students and a random sample of vignettes drawn from the population of possible vignettes (all possible combinations of values of vignette dimensions). Our statistical models disentangle person-specific effects from vignette-specific effects and test for select cross-level interactions between person and vignette characteristics.

\section{Population and Sample of Respondents}

In 2012, we administered a web-based version of our factorial survey experiment to a sample of undergraduate students enrolled at a large public research university. This university is the state's flagship and has a relatively diverse student body. Moreover, recent tuition increases have spurred discontent among students, who are at risk of protest. In response to an announced tuition increase of 14 percent, hundreds of the approximately 28,000 possible students at this university staged a protest on campus in March of 2010 to coincide with a “National Day of Action” organized by a coalition of American student groups. The following year, another tuition increase of 20 percent elicited a protest involving only a few dozen students. Clearly, the issue of tuition is salient for students at this university but there has been temporal variation in the magnitude of protests against tuition increases.

Using the registrar's listing of students and email addresses, we drew a disproportionate stratified random sample of freshmen, sophomores, and juniors. We stratified by membership in a student organization to ensure we sampled sufficient numbers of politically active students. 
Our final sample of 207 students reflects a CASRO-4 response rate of 45 percent and a cooperation rate of 80 percent. $^{9}$

\section{Vignette Dimensions and Levels}

A crucial task for implementing factorial surveys is to create vignette dimensions and levels that not only capture key theoretical concepts such as selective incentives and protest frames, but also comprise theoretically plausible protest scenarios (see Appendix A, Parts A and B). In creating the vignette characteristics, we drew upon the literatures on student protests, collective action, and rational choice, as well as preliminary focus groups and a pilot study (see Appendix A, Part C). In our scenarios, we assume two exogenously given actors-a university administration and a student organization—which set incentive levels and provide information. ${ }^{10}$

The first dimension we manipulate is the magnitude of the grievance imposed on students. In our vignettes, the grievance is the size of the tuition increase threatened by the university administration. We distinguish between four levels of grievance-1\%, 10\%, 50\%, and 100\% tuition increase - that are plausible and in the range of real-life tuition increases. Quebec and Puerto Rico, for instance, have proposed 75\% and 100\% increases in the past, respectively. To state it differently, preventing a tuition hike determines the value of the collective good: the greater the grievance (i.e., tuition increase), the greater the value of the collective good if the tuition hike is thwarted.

\footnotetext{
${ }^{9}$ We had 56 refusals and 232 cases in which the student did not respond to our email. A comparison of respondents with non-respondents on class standing and gender revealed no appreciable differences. Although our primary interest is in making model-based statistical inferences, we also constructed sampling weights based on our disproportionate stratified sample of students, re-estimated our models using weights, and found similar results. ${ }^{10}$ Outside organizations sympathetic to a cause do contribute resources to student protests. For example, in the 1990s, the AFL-CIO provided funds to support student activism against sweatshops (Van Dyke et al. 2007). In 1999, labor unions and fair-trade groups provided substantial subsidies to radical student groups involved in protests against the World Trade Organization meeting in Seattle (Murphy and Pfaff 2005).
} 
We include two dimensions of selective incentives and disincentives. The first dimension captures the university administration’s attempt to increase the costs of protesting, which historically has ranged from minor informal sanctions (e.g., reprimands) to serious academic sanctions (e.g., expulsion) to legal sanctions (arrest) (McCormick 1990; Wood 2014). We focus on a salient cost to students easily imposed by administrators - punitive grading and expulsion. This dimension, selective punishments, ranges from no penalty to incomplete grades to failing grades to expulsion from the university. Our second dimension of selective incentives, selective rewards, operationalizes benefits awarded by a student organization for participating in the protest. Following Olson (1965), we include four levels of up-front monetary rewards to participants, including a blank level (i.e., respondents shown nothing), \$10, \$50, and \$200. Here, \$10 is a plausible return from a sponsoring organization, such as a labor union. We include \$50 and \$200 to test counterfactual conditions of strong incentives. In our operationalization, selective rewards are available to all participants regardless of group size, making them structurally similar to selective punishments (Oliver 1980).

We employ two dimensions to capture social incentives. The first, social inducement, operationalizes the strength of social ties to peers who try to recruit the respondent, including no one, an acquaintance, one friend, and three friends (Opp and Gern 1993; Schussman and Soule 2005). Here, we are assuming (1) that respondents can imagine hypothetical recruitment scenarios (which might depart from their actual expectations), and (2) that respondents recruited by others must overcome the cost of others' disappointment if they are to refrain from participating. The second dimension, reputational incentives, captures respect and admiration from significant others for participating (Chong 1991; Willer 2009). This consists of two 
conditions: a blank level and a level in which friends and family admire anyone who would participate. ${ }^{11}$

We use three dimensions to capture framing effects. Each dimension contrasts an objective scenario corresponding to a negative frame with alternatives corresponding to increasingly positive frames. We assume that subjective frames are rooted in objective reality, and therefore respondents will subjectively frame the situation in ways consistent with the objective dimension. Solidarity frame depicts a student organization saying that "solidarity is the only defense against social injustice,” which diagnoses the problem, attributes wrongdoing, and proposes a solution. Efficacy frame provides information about the success of walkouts aimed at stopping tuition increases at other universities. This captures high collective efficacy that could provide a motivational solution for collective action (Nelson et al. 1997). Injustice frame further diagnoses the problem and attributes wrongdoing by depicting a violation of fairness norms: “administrators are planning a 10\% increase in their salaries.” Such a violation should produce anger, and consequently, increase the expected gain (justice) from a successful protest (Gamson 1990).

The final vignette dimension, number of participants, consists of the cumulative number of protesters who have already joined the protest. This allows us to test the static implications of critical mass theories and estimate a production function. ${ }^{12}$ Given the undergraduate population

\footnotetext{
${ }^{11}$ Social inducement and reputational incentives provide "what if" counterfactuals. They require the respondent to imagine a scenario in which friends attempt to induce participation and friends and family will admire protest behavior - even if the respondent's actual friends and family are unlikely to act in this way. If respondents are unable to imagine such a scenario, the manipulation fails and effects will be underestimated. We expect such bias will be minimal, as research suggests individuals are quite adept at imagining "what if" counterfactuals even if their real-life situations do not parallel those described in the hypothetical situation (Kahneman 2011), and such counterfactuals have been used effectively in previous factorial surveys (Wallander 2009).

${ }^{12}$ We follow Glaeser et al. (1996) and others in empirically modeling the static implications of a dynamic process. The use of conventional empirical methods, such as longitudinal data on individuals as they sequentially decide to protest, is virtually intractable. Such a design would require moment-by-moment data on individual decisions and a model of how such decisions are sequentially dependent.
} 
of nearly 28,000 students, we used 12 categorical variables to capture variation in the number of participants (0, 1, 5, 20, 100, 250, 500, 1000, 5000, 10000, 20000, and 25000) (see McGloin and Thomas 2015 for a similar strategy). We assume that small differences at low numbers (e.g., between 0 and 1) are more important than small differences at large numbers (e.g., 10000 and 10001), and seek to capture meaningful variation at the low end of the scale, including potential first movers. By regressing likelihood of success on the contributor dummies, we obtain a nonparametric estimate of the shape of the effect, which gives us an estimate of the average production function across the population. ${ }^{13}$

These nine vignette dimensions and their respective levels generate a factorial object universe of 49,152 $\left(2^{4} \times 4^{4} \times 12^{1}\right)$ unique vignettes. ${ }^{14}$ We showed respondents ten vignettes randomly drawn with replacement from the vignette object universe of 49,152 unique vignettes, yielding a vignette-level sample of 2,070 vignettes and an individual-level sample of 207 respondents. ${ }^{15}$

\section{[Table 1 about here]}

\section{Endogenous Variables}

For each vignette, respondents completed two evaluation tasks-each involving 0 to 100 probability scales — that constitute our endogenous variables (see Appendix A). First,

\footnotetext{
${ }^{13}$ Given assumptions of the critical mass theory (footnote 5), respondents' estimates of the likelihood that protests will succeed (as depicted in the vignettes) is an unbiased estimate of the true aggregate likelihood of success. ${ }^{14}$ Methodological research on vignettes find that 12 dimensions may produce inconsistent evaluations and learning effects, whereas 8 dimensions does not, and that fatigue or boredom sets in after evaluating 10 vignettes (see Sauer et al. 2011; Robbins and Kiser 2018). Research also finds that order effects appear with complex evaluation tasks and when respondents lack certainty of judgments (Auspurg and Jäckle 2017). We guard against these problems by using 9 dimensions, assigning 10 vignettes to respondents, and using relatively simple evaluation tasks (likelihood of success and intention to protest).

${ }^{15}$ Using simple random sampling implies that our factorial object universe is much greater than the overall sample size (our sampling fraction is .043). The resulting sparseness has little effect on estimating main and low-level interaction effects, but reduces the power of tests of higher-order interaction effects, which are of less interest in our models (Alexander and Becker 1978 call this “aliasing”). According to Dülmer (2016, p. 340), "One strength of simple random designs is their low susceptibility to systematic biases as might be caused for fractional factorial designs and for D-efficient designs by their aliasing structure.”
} 
respondents were asked the likelihood that the student walkout would succeed (likelihood of success). We treat likelihood of success as a potential mediating variable between incentives and willingness to protest. We employ expectations elicited in probabilistic form for three reasons. First, probabilities represent the level of the collective good provided in many production functions (Oliver et al. 1985). Second, probabilities provide a well-defined numerical scale that allows interpersonal comparisons. Third, probabilities allow respondents to express uncertainty when assessing scenarios that lack full information. We use probabilistic scales for both likelihood of success and intention to protest. The mean probability of expected success averaged across our vignettes and respondents is .36 (see Table 1), which supports the realism of our vignette universe.

Second, respondents were asked the probability that they would participate in the walkout (intention to protest), which measures willingness to join the protest—our primary dependent variable. The mean intention to protest averaged across vignettes and respondents is .40. Thus, given our vignettes, students report a substantial willingness to protest tuition hikes, which suggests that tuition increases are a salient political issue and there is no universal tendency toward free riding.

Theoretically, we are interested in explaining individual differences in willingness to protest rather than actual protest behavior. Although some sociologists have criticized the use of intentions or expectations_-such measures are imperfectly associated with behavior (Finkel and Muller 1998)_ _others argue that intentions are appropriate to model (Fishbein and Ajzen 1975; Finkel et al. 1989). As Manski (1990, p. 940) notes, divergences between measures of intentions and behavior "may simply reflect the dependence of behavior on events not yet realized at the time of the survey.” Thus, even if intentions are the best predictors of behavior, they will diverge from observed behavior when relevant information—such as objective social context- 
changes. We examine this question empirically by systematically varying social context via our vignettes.

We regress intention to protest on success to test the hypothesis that those respondents who believe the protest will succeed will have a greater willingness to protest. As noted above, research suggests that the greater the likelihood that a protest will succeed in securing the public good, the more likely individuals will participate. Moreover, we can test for indirect effects, mediation, and the hypothesis that perceived number of participants increases willingness to protest because it increases the perceived likelihood of success of the protest (Opp 2009).

\section{Stable Preferences and Demographic Characteristics}

Table 1 presents brief descriptions and summary statistics of demographic characteristics and individual preferences. Among our stable preference variables, we use three measures of previous protest activity: ever organized a protest, prior membership in organizations (a 9-item scale), and prior participation in various forms of activism (a 9-item scale). Identity is measured in three ways: current member of a political activist student organization, identification as a student (3-item scale), and self-efficacy (10-item scale taken from Schwarzer and Jerusalem 1995). We use multiple measures of attitudes about grievances, attitudes about protests, and cooperative preferences. We capture perceived structural grievances toward the university with a 4-item scale. We use three measures of protest attitudes: protests are justified, the goal is more important than the act of protest, and a respondent will protest despite likely failure. We measure cooperative versus individualist values using the triple dominance scale of social values, a well-researched construct in psychology (Van Lange et al. 1997). We measure attitudes about the tuition increase (grievance) by asking whether tuition increases are justified. Finally, we capture risk taking with a well-established item (see Table 1). We also control for a 
number of demographic and political characteristics, including political orientation, age, race and ethnicity, gender, education, income, economic independence, and state residency.

\section{Structure of the Model}

Our model is diagrammed in Figure 2. We regress likelihood of success on vignette dimensions that operationalize social context—collective good (expected gain), selective incentives, number of participants, and frames. We expect the number of participants to increase perceived success, tracing out the production function. Holding constant current number of protesters, selective incentives, and expected gain may affect success directly: when incentives are positive, forward-looking actors will expect the number of protesters to increase beyond the current number, which in turn will increase their perceptions of success. The same holds for collective action frames.

\section{[Figure 2 about here]}

We regress intention to protest on likelihood of success and vignette characteristics. We expect success to affect intentions directly, as no one wants to join a protest doomed to failure. Moreover, we expect elements of social context to affect willingness to protest directly, as well as indirectly through perceived success. For example, the current number of protesters will affect intentions indirectly by increasing the likelihood of success—a hypothesis of safety in numbers. But the current number of protesters may affect intentions directly as well, as greater numbers of protesters induce stronger protest identities (see Calhoun 1991). Similarly, we hypothesize that selective incentives will affect protest intentions directly, a self-regarding effect. But selective incentives may also affect intentions indirectly by affecting perceived success. This is an other-regarding effect: actors anticipate that incentives will induce future others to join the protest, which increases perceived success, and ultimately increases intentions to protest. 
We also regress likelihood of success and intention to protest on stable preferences and demographic characteristics, and test for cross-level interactions between individual characteristics and social context.

\section{A Multi-Level Structural Equation Model for Censored Data}

We estimate two-level structural equation models for censored outcomes that allow us to test whether likelihood of success mediates the effects of vignette characteristics on intention to protest (see Figure 3). The first level models within-person variation by regressing likelihood of success and intention to protest—each measured on probability scales bounded by 0 and 100 on vignette characteristics. Intention to protest appears censored from both above and below (with clumping at 0 and 100), while our measure of likelihood of success appears censored from below (only clumping at 0) (see Figure B1 in Appendix B). Therefore, we use a Tobit model to correct for censoring since linear models yield downwardly biased estimates in the presence of floor and or ceiling effects (Long 1992). ${ }^{16}$

\section{[Figure 3 about here]}

If we let $M_{i j}$ be our observed measure of likelihood of success for vignette $i$ and individual $j$, our first-level model for likelihood of success takes the following form:

Likelihood of Success: $M_{i j}^{*}=\alpha_{j}^{M *}+X_{i j} \gamma+\delta_{i j}$

where $m_{i j}=\left\{\begin{array}{l}M_{i j}^{*} \text { if } M_{i j}^{*}>\tau_{l} \\ \tau_{l} \text { if } M_{i j}^{*} \leq \tau_{l}\end{array}\right.$

and $M_{i j}^{*}$ is a latent continuous (unbounded) measure of perceived likelihood of success, $\alpha_{j}^{M *}$ is a random intercept term capturing unobserved heterogeneity varying across individuals but not

\footnotetext{
16 The Tobit model corrects for censoring but also makes a number of strong assumptions. A sensitivity analysis shows that our results are robust to these assumptions (see Appendix B).
} 
vignettes, $\gamma$ is a (non-random) coefficient vector, $X_{i j}$ is a vector of vignette characteristics varying across both individuals and vignettes, $\delta_{i j}$ is a disturbance term (assumed normal and iid), and $\tau_{l}$ is a lower threshold. This defines our first level model of likelihood of success, which is a betweenvignette within-individual model.

Similarly, if we let $y_{i j}$ be our observed measure of intention to protest for vignette $i$ and individual $j$, our first-level model for intention to protest takes the following form:

Intention to Protest: $Y_{i j}^{*}=\alpha_{j}^{Y *}+M_{i j}^{*} \beta+X_{i j} \phi+\varepsilon_{i j}$

where $y_{i j}=\left\{\begin{array}{l}\tau_{u} \text { if } Y_{i j}^{*} \geq \tau_{u} \\ y_{i j}^{*} \text { if } \tau_{u}>Y_{i j}^{*}>\tau_{l} \\ \tau_{l} \text { if } Y_{i j}^{*} \leq \tau_{l}\end{array}\right.$

and $\alpha_{j}^{Y *}$ is a random intercept term capturing unobserved heterogeneity varying across individuals but not vignettes, $\beta$ is a (non-random) coefficient, $\phi$ is a vector of (non-random) coefficients, $Y_{i j}^{*}$ is a latent continuous (unbounded) measure of intention to protest, $X_{i j}$ is a vector of vignette characteristics varying across both individuals and vignettes, $\varepsilon_{i j}$ is a disturbance term (assumed normal and iid), and $\tau_{u}$ and $\tau_{l}$ are upper and lower thresholds, respectively.

We can decompose the total effects of our vignette characteristics $X_{i j}$ on intention to protest $Y_{i j}^{*}$ into direct and indirect effects through likelihood of success $M_{i j}^{*}$ by substituting eq. (5) into eq. (7), which yields the following:

Protest Reduced Form: $Y_{i j}^{*}=\alpha_{j}^{Y *}+\alpha_{j}^{M *} \beta+X_{i j}(\gamma \beta+\phi)+\delta_{i j} \beta+\varepsilon_{i j}$ where $\alpha_{j}^{T}=\alpha_{j}^{Y *}+\alpha_{j}^{M *} \beta$ is the effect of intercepts, $\pi=\gamma \beta+\phi$ is the total effect of vignette characteristics, and $\varphi_{i j}=\delta_{i j} \beta+\varepsilon_{i j}$ is the reduced-form disturbance term. Following convention, we first test for a total effect $\pi$, and then decompose it into direct and indirect effects. The 
hypothesis of total mediation by $M_{i j}$ is the test of $\phi=0$. We use the delta method to obtain asymptotic standard errors for indirect and total effects (Sobel 1982).

We specify second-level models of between-person variation in likelihood of success and intention to protest by modeling our random intercepts (see Figure 3):

Likelihood of Success: $\alpha_{j}^{M *}=a+Z_{j} \Gamma+u_{j}$

Intention to Protest: $\alpha_{j}^{Y *}=b+Z_{j} \rho+\alpha_{j}^{M *} \eta+v_{j}$

where $\alpha_{j}^{M *}$ and $\alpha_{j}^{Y *}$ are random intercept terms from above capturing individual variation in likelihood of success and intention to protest, respectively, $a$ and $b$ are non-random intercepts, $Z_{j}$ is a vector of individual characteristics, $\Gamma, \rho$, and $\eta$ are non-random coefficients, $u_{j}$ and $v_{j}$ are uncorrelated disturbance terms (assumed normal and iid). Our second-level models estimate effects of individual-level covariates on variation in likelihood of success and intentions to protest across individuals. ${ }^{17}$ Thus, $\Gamma$ represents the effect of individual characteristics $Z_{j}$ on likelihood of success, and $\rho$ gives a similar effect on intention to protest (Figure 3). Similarly, $\eta$ represents the effect of individual judgments of success (averaged across vignettes) on intention to protest. ${ }^{18}$ By substituting eq. (10) into eq. (11) we can decompose our individual-level effects into direct effects and indirect effects through success (averaged across vignettes).

By stacking $Y$ and $M$ for each unit $i$ within $j$, we can estimate our equations simultaneously as a single system using maximum likelihood estimation (Hayes 2013). This provides consistent and asymptotically efficient estimates of parameters and consistent estimates of standard errors. We estimated our models using the generalized structural equation module (GSEM) in Stata 13.1.

\footnotetext{
${ }^{17}$ Note the parallel that obtains with contextual effects models of group effects when individuals (level-1) are nested within groups (level-2). In our models, individuals (level-2) serve as “contexts” after controlling for between-vignette variation (level-1).

18 The aggregate effect of, for example, success (averaged across vignettes) on intentions (averaged across vignettes) is the sum of the level-1 and level-2 coefficients $(\beta+\eta)$.
} 


\section{Results}

We decompose the variance of our endogenous variables, likelihood of success and intention to protest, into within- and between-person variation by estimating an empty random intercept model (Raudenbush and Bryk 2002). This yields an intra-class correlation of .24 for success and .29 for protest. Thus, 24 percent of the variance of success and 29 percent of the variance of protest is between individuals, with the remainder within individuals (i.e., across vignettes). The significant variation between individuals and vignettes justifies the use of multilevel models.

\section{Individual Level: Preferences and Demographics}

Table 2 presents results of our level-2 equation, which investigates the total effects of individual-level characteristics_-propensities, preferences, and demographics—on individualspecific means (i.e., random intercepts) of likelihood of success and intention to protest. Our control variables, race-ethnicity and gender (Table 2) as well as class standing and income (not shown), are not significantly associated with likelihood of success or intention to protest. Liberals are significantly more likely to protest than moderates, but not more than are conservatives. Regarding the effects of preferences, our measures of identity — student identity, self-efficacy, and current member of a political student organization-affect neither success nor intention to protest. Surprisingly, controlling for other covariates, previous protest participation and previous activism are not significantly associated with likelihood of success or intention to protest.

\section{[Table 2 about here]}

We do find significant effects for our measures of attitudes toward grievances and protests. As expected, students who report that they would participate in a protest even if it was unlikely to succeed are more prone to protest (6 percentage points) and more likely to view the 
protest as succeeding (3.5 percentage points). Students who believe it is justified to participate in a protest when grievances are ignored have a greater intention to protest and a greater perception of the protest's success in our scenarios than students who believe otherwise. As hypothesized, students who have cooperative social value orientations have a higher intention to protest than do those with egoistic orientations. Risk-taking individuals have a greater intention to protest and are slightly more optimistic about a protest's success than those who are riskaverse.

Overall, we find some support for the effects of stable preferences and demographic characteristics on individual-specific means of likelihood of success and intentions to protest. We turn now to the heart of our model, the effects of vignette characteristics.

Vignette Level: Collective Good, Incentives, and Frames

Our level-1 equations regress likelihood of success and intention to protest on vignette characteristics. We first present total effects for likelihood of success and intention to protest (Table 3), followed by direct and indirect effects of vignette characteristics on intention through perceived success (Table 4).

[Table 3 about here]

Likelihood of Success. Column 1 of Table 3 presents total effects of vignette characteristics for likelihood of success (depicted by the vector $\phi+\gamma \beta$ in Figure 3). Our grievance dimension — tuition increases—strongly influences the likelihood that the protest will succeed. We reject the null hypothesis that the three dummies are jointly equal to zero $\left(\chi^{2}(3)=\right.$ $59.4, p<.001)$. A $10 \%$ increase in tuition generates a .05 greater perceived likelihood of success than a $1 \%$ increase in tuition. This effect is monotonic: compared to a $1 \%$ increase in tuition, a $50 \%$ increase produces a .10 greater likelihood of success than a $1 \%$ increase, while a $100 \%$ 
increase in tuition yields a .14 greater likelihood of success. Thus, as expected, students recognize that grievances are effective in galvanizing student protest.

We also find that monetary incentives have a significant but modest effect on likelihood of success $\left(\chi^{2}(3)=11.9, p<.001\right)$. Only when a student organization offers a $\$ 50$ or a $\$ 200$ incentive for participating — not a \$10 incentive—-does the likelihood of success increase. Even then, the effect sizes for $\$ 50$ and $\$ 200$ are negligible with the likelihood of success .04 and .05 greater than the no monetary incentive condition, respectively. Of greater practical importance are selective disincentives threatened by the university $\left(\chi^{2}(3)=65.0, p<.001\right)$. The likelihood of success is reduced by .04 for threats of an incomplete grade, by .10 for threats of a failing grade, and by .11 for threats of expulsion. Thus, from the students’ perspectives, a university crackdown threatening students with salient penalties undermines the goal of a protest. By contrast, our social incentive variables have little effect: perceived likelihood of success does not significantly change with recruitment by peers $\left(\chi^{2}(3)=0.9, p>.05\right)$ or respect and admiration from significant others (see Table 3). Similarly, none of our three collective action frames—solidarity, efficacy, and injustice—significantly predict success (see Table 3).

\section{[Figure 4 about here]}

Next, we explore the functional form between the size of the protest and perceived likelihood of success, which traces the production function. Using dummy variables for number of participants to provide a nonparametric estimate, we find a decelerating functional form: increasing the number of participants from 0 to 1000 precipitously increases the average probability of success from less than .10 to about .35 (see Figure 4, Panel A). At this point, the increase reaches an inflection, leveling off until about 20,000 participants, with a maximum probability of about .70. Thus, when 1,000 students (3.5\%) is mobilized, the likelihood of success is .35, approximating a tipping point at which problems of "optimization, strategic 
action, surplus, and free riding” kick in, causing the probability of success to flatten (Oliver and Marwell 2001: 295). When 5,000 students participate (18\%), the likelihood of success is just under $.45 .^{19}$ Under the assumption that individuals are aware of the shape of the production function (footnote 5), this estimates the production function where number of participants is the measure of resources and perceptions of success probabilities aggregated across respondents captures population likelihood of success. These findings assume that respondents are treating the numerical labels of categories-e.g., 500 versus 1,000-as real numbers, rather than merely ordinal categories. To test this assumption, we drew an independent random sample of students and used a log-scale to define numerical categories, and found very similar results (Robbins et al. 2020).

The decelerating production function, reflecting decreasing marginal returns (see Figure 1, Panel C), is consistent with Olson’s (1965, p. 29) expectation of “exploitation of the great by the small.” Earlier initiators and first movers_-presumably those with the greatest interest in the public good — bear a disproportionate amount of the burden, while those who delay their contributions can free-ride on the efforts of others. As a result, contributions are likely to be inefficient due to order effects. An efficient ordering would have the least interested contributing first with the most interested contributing last when marginal returns diminish (Oliver et al. 1985). We found that by treating the categorical labels as real numbers and assuming a continuous distribution, a quadratic term captured the decelerating functional form nearly as well as the nonparametric dummies. We therefore report the more parsimonious parametric quadratic model in Table 3.

\footnotetext{
${ }^{19}$ We produced the graphs in Figure 4 by treating the anchor points from our measure as real numbers represented by 11 dummy variables to estimate the functional form non-parametrically. In later results, we treat the anchor points as real numbers representing an interval scale and approximate the functional form using linear and quadratic terms. Our statistical tests reveal that the quadratic model captures the nonlinearity quite well.
} 
Intention to Protest: Total Effects. Column 2 of Table 3 presents total effects, depicted by the vector $\pi=\gamma \beta+\phi$ (eq. 9), for our key dependent variable intention to protest. We find that the magnitude of the grievance-tuition increases — substantially affects intention to protest $\left(\chi^{2}(3)=161.5, p<.001\right)$. This effect is monotonic: compared to a $1 \%$ tuition increase, an increase of $10 \%$ produces a .09 greater probability of willingness to protest, while tuition increases of $50 \%$ and $100 \%$ produce a .22 and a .36 increase in protesting. Thus, contrary to Olson (1965) and some resource mobilization theorists, net of other factors the magnitude of a grievance is crucial in mobilizing political protest.

Consistent with Olson (1965), monetary incentives exert a significant but modest effect on intention to protest $\left(\chi^{2}(3)=18.2, p<.001\right)$. While a mere $\$ 10$ incentive has no significant effect, \$50 generates a .06 increase in the probability of willingness to protest and \$200 produces a .10 increase. Thus, with substantial monetary resources, student organizations can influence the size of student protests against tuition increases. Consistent with Olson (1965), selective disincentives threatened by the university significantly affect intentions $\left(\chi^{2}(3)=124.6\right.$, $p<.001)$. The threat of an incomplete grade reduces the probability of intentions by .14 , the threat of a failing grade reduces the probability by .26, and the threat of expulsion drops it by .29. Clearly, students respond to salient disincentives administered by the university.

Turning to our social incentive variables, we find that intention to protest does not significantly change with recruitment by friends $\left(\chi^{2}(3)=2.85, p>.05\right)$ or with respect and admiration from significant others for participating (see Table 3). Our efficacy and solidarity frames also exert little influence on participation (see Table 3). Our injustice frame shows an effect in the 
expected direction - intention to protest is greater when top administrators are planning to increase their salaries by ten percent—but the coefficient is statistically indistinguishable from zero. ${ }^{20}$

Paralleling likelihood of success, current number of protesters has a strong effect on intentions to protest. Using eleven dummy variables to estimate the functional form nonparametrically, we find a decelerating function: as the number of participants is varied from 0 to about 500, the intention to protest precipitously increases from less than .20 to nearly .35 (see Figure 4, Panel B). At this point, the effect of more participants on intention to protest flattens out, reaching a maximum of about .70 when 25,000 students are participating. Early movers exert the strongest effect on mobilizing others to a protest, reaching an inflection point at about 500 protesters. Thus, we find negative interdependence in which the returns to participation decline with the number of individuals participating. Again, this suggests inefficiencies in participation: the most committed protesters are likely to join early when returns are high, leaving the less committed to free ride later when returns are low. By treating the values of the dummy variables as real numbers, we find a quadratic model fits the data nearly as well as the dummy variables: a positive linear term and negative quadratic term traces a decelerating curve (see Table 3).

Intention to Protest: Direct and Indirect Effects. We regressed intention to protest on all vignette and individual characteristics as well as perceived likelihood of success (Figure 3). ${ }^{21}$ Examining the relation across vignettes (i.e., level 1), we find the effect is substantial and significant: a change of .10 in the probability of success is associated with a .095 change in the probability of intentions to protest. The standardized coefficient is .82. Thus, as hypothesized, students are more likely to participate when they expect the protest to succeed.

\footnotetext{
${ }^{20}$ Material selective incentives, particularly the negative sanctions, could conceivably crowd out the effects of more nuanced concepts such as collective action frames. Empirically, this implies an interaction between sanctions and frames: when sanctions are not imposed, frames should predict protest. Our tests of this hypothesis were unsupported.

${ }^{21}$ For space considerations, we do not report indirect effects that are both trivial in size and statistically nonsignificant. Full models are available upon request.
} 
[Table 4 about here]

In Table 4, we decompose the vignette characteristics that exhibited a significant total effect on participation into direct and indirect components. ${ }^{22}$ First, we consider the size of the grievance. The greater the threatened tuition increase, the greater the public good created by a successful protest. Larger increases in tuition cause students to believe that the protest will succeed, which induces protest participation. This indirect effect explains nearly half of the total effect of a $10 \%$ tuition increase on participation and nearly two-fifths of the total effect of $50 \%$ and 100\% tuition increases (relative to a 1\% increase) (see Table 4). Stated differently, a 100\% tuition hike is associated with a .14 increase in the probability of intentions to protest because it increases the probability of success (compared to a .22 direct effect). Thus, large grievances induce participation because they are associated with perceptions of a higher probability of success of a protest.

We find a similar result for selective incentives. A \$10 incentive had a negligible effect on intention to protest, but incentives of \$50 and \$200 had significant effects. A \$50 incentive for protesting increases willingness probability by .06 with nearly three-fourths of this effect operating indirectly through likelihood of success (see Table 4). For a \$200 incentive, half of the .10 total effect operates through success. Thus, selective incentives directly motivate students to participate by offsetting the personal costs of protesting, but also indirectly as students recognize that offering selective incentives to all students increases the likelihood that a protest will succeed. We find a similar result for selective disincentives. Students threatened with an incomplete grade have a .14 lower probability of intention to protest, and nearly one-fourth of

\footnotetext{
${ }^{22}$ We also decomposed the total effects of preferences and demographic characteristics on intention to protest into direct and indirect components, but in nearly every case the indirect effects are dwarfed by direct effects. We also found a few small cross-level interaction effects, but they did not affect our substantive conclusions. We did not find an interaction between incentives and group size as did McGloin and Thomas (2015) in their models of collective vandalism. These results are available upon request.
} 
this operates indirectly through lowered success (see Table 4). The corresponding indirect effects for failing grades and expulsion are a little less than two-fifths of the total effect. Thus, when students are threatened with lower grades they are less likely to protest mainly because of the personal costs of a lower grade or expulsion (direct effect), but also in part because they realize the protest is less likely to succeed when all students are threatened with punitive grades (indirect effect).

Finally, we test the hypothesis that the current number of participants indirectly affects intention to protest by affecting the likelihood that the protest will succeed. Recall that we found a decelerating curve for both success and participation as a function of number of participants. When we decompose the total effect of number of participants on intention to protest into direct and indirect effects, we find the indirect effect dominates: Intention to participate is a positive decreasing function of the current number of participants because the number of participants increases the likelihood of success. This supports Opp’s (2009) hypothesis that perceived current number of participants affects protest indirectly through perceived success. Indeed, the indirect effect is larger in magnitude than the total effect. This results in a direct effect that is opposite in sign (for both linear and quadratic terms), which could be due to sampling variability (given the magnitude of the linear relationship between success and intention), even though it is statistically distinguishable from zero.

\section{Discussion and Implications}

Our empirical analysis of student protest yields five principal results. First, contrary to the Olsonian paradigm, the magnitude of the grievance (tuition increase) is important for perceived success of the protest as well as intention to protest. Second, consistent with Olson's theory of selective incentives, we find that selective rewards and punishments predict propensity to protest, and find little evidence for non-pecuniary rewards, such as reputation among 
significant others. Rather than indicating that social influence is ineffective, our finding accords with Olson's expectation that "soft” incentives are ineffective in large groups. Third, collective action frames (at least as operationalized in our study), including efficacy and injustice, make little difference in decisions to protest. Fourth, the current number of participants in a protest is positively associated at a diminishing rate with both the likelihood of success and the intention to protest, implying decelerating production and mobilization functions. Fourth, the likelihood of success mediates much of the effect of social context on propensity to protest.

The effect of grievances can be explained by rational choice: the greater the threatened tuition increase, the greater the returns - in the form of the public good - to a protest that thwarts the increase. The result is also consistent with the proposition that incidental or suddenly-imposed grievances may be more effective in motivating protest than long-standing structural grievances, such as economic inequality (van Zomeren et al. 2008). Suddenlyimposed grievances, like tuition hikes, may create common interests across an otherwise diverse population and generate expectations that others will not stand for them. The result is more protest under conditions of incidental grievances than structural grievances.

The clearest evidence in support of Olson's rational actor model is the significant effect of positive and negative selective incentives administered by the student organization and the university administration, respectively. Note, however, that a \$10 incentive was marginally associated with success and non-significantly associated with intent, whereas incentives of \$50 and \$100 exerted significant effects on both success and intent. It is hard to imagine a student organization or sponsoring union having the resources to reward protesters with $\$ 100$, or even \$50, for participating. Nevertheless, our vignette approach allows us to consider such theoretically relevant counterfactuals. More generally, in most instances of collective political action, organizers are unable to offer selective incentives to all participants of large protests, 
while political authorities can and do credibly sanction all participants. Oliver (1980) refers to this as the asymmetry between rewards and punishments. Whereas much of the literature has focused on social incentives activated through network ties, we show that material rewards are relevant to public-spirited collective action, a finding at odds with studies warning that pecuniary appeals may undercut cooperation (Fehr and Gintis 2007). In some populations, particularly heterogeneous ones lacking dense social ties, paying to induce cooperation may be an effective strategy to overcome the start-up problem identified in critical mass theory. While most solutions to the free rider problem rely on social and other non-material incentives to induce early participation (Centola 2013), monetary payment may be a viable alternative when resource-rich organizations already exist and social ties are relatively sparse. Olson (1965) recognized this point when discussing unions: labor organizations use mandatory membership dues to compensate organizers with monetary payments, induce new members to join, and subsidize the costs of participating in strikes.

Our study has important implications for rational choice models of behavior. The findings show how actors are simultaneously self-regarding and other-regarding, with their intentions to act influenced by what they believe others will do in the same situation. Two of our results speak to this. The first provides evidence against Olson’s (1965) implicit assumption of independent actors and in favor of theories of interdependence (Marwell and Oliver 1993; Granovetter 1978). The finding of significant effects of number of participants on willingness to protest suggests interdependent decision-making: students consider the actions of other students in making their own decisions, and believe in something like "safety in numbers" (Granovetter 1978). The decelerating mobilization and production functions imply that returns to participation are greater early on, as protesters feel they can make a difference. Later on, free riding becomes a problem, as individuals with the greatest interest are likely to contribute first, 
leaving less interested individuals to free ride_-resulting in underinvestment and inefficiencies. The second finding — selective incentives operate both directly and indirectly through perceived success_-suggests that individuals consider the effect of selective incentives not only on their own behavior, but also on the behavior of others. Incentives directly affect one's perception that a protest will succeed-presumably because one assumes that incentives will motivate others to protest - which in turn increases one’s willingness to join a successful protest. ${ }^{23}$

Our analysis of production functions responds to Oliver and Marwell’s (2001) call for (a) models of collective action that recognize the range of incentives and explicitly state what is being held constant and what is being varied; and (b) a move from agent-based simulations to empirical observations. Our vignette approach has attempted to address these issues. However, we have not examined an important feature of critical mass theory. Namely, the effect of group heterogeneity in resources on production functions and mobilization functions. This is important for future research since heterogeneous groups are more likely to have a critical mass of highly resourced individuals capable of overcoming the free rider problem. Future research on student protest should compare different universities that vary systematically in the distribution of interests and resources among students. For example, given a decelerating production function, does heterogeneity of interests but not resources matter for a critical mass to form, as argued by Oliver et al. (1985)?

In sum, our results support a rational actor model which modifies the assumption of independent actors. Nevertheless, several caveats are in order. First, our null findings for collective action frames should be treated carefully. We operationalized frames with objective

\footnotetext{
23 The finding of dependence among actors has important implications for individual-level statistical models of collective action. These models typically assume that observations are independent across individuals and across time. Our results suggest a need to model such dependence with, for example, spatial and temporal autoregressive components to ensure unbiased estimates and warranted conclusions.
} 
vignette dimensions representing solidarity, injustice, and efficacy frames. We assume that respondents perceive these dimensions as frames for solidarity, injustice, and efficacy, imbuing them with corresponding meanings. This strategy has the strengths of (1) manipulating perceived meanings in an experimental setting in a way that simulates how political organizations might seek to manipulate such meanings, and (2) operationalizing meanings without resorting to the difficult process of measuring psychic phenomena or inferring meanings from observations of interactions. Our method is more systematic than alternative approaches, but assumes that the vignette dimension captures the specific frame and that respondents react to the frame as hypothesized. Moreover, we are capturing a snapshot of a collective action frame and not the dynamic and evolving process of aligning frames to fit with preexisting perspectives of various constituent groups (Snow et al. 1986). Future research should examine these assumptions.

Second, critics have claimed that factorial survey experiments create unrealistic situations and are subject to response bias. To avoid this, we conducted focus groups and pretests of our vignettes. Nevertheless, critics might argue that some combinations of our vignette dimensions and responses may undermine the legitimacy of the experiment, such as 20,000 students are protesting and protesters are paid $\$ 200$, which, if multiplied out, implies that 5 million dollars are being distributed. If respondents were full information utility maximizers, they may have deemed the scenarios as unrealistic and provided biased responses. To test for this, we re-ran our analyses dropping vignettes that included counterfactual values (e.g., \$200 incentives, expulsion from school, and more than 5000 student protesters), thus eliminating potential loss of legitimacy. Our results remained similar. Moreover, our model assumes bounded rationality, in which actors are using shortcuts, limited information, and rules of thumb, not only for collective action but also for response behavior. Our finding that 
respondents evaluated the ten vignettes in about ten minutes is consistent with bounded rationality and inconsistent with a model of respondents carrying out mathematical calculations to determine the legitimacy of the study.

Third, our dependent variable is intention to protest, rather than actual protest behavior. While we argue that the conditions under which students are willing to protest is a key component of the process producing actual protest behavior (Klandermans 1984), critics may question whether our measure of willingness is related to actual protest behavior. To examine this question, we conducted a follow-up survey on a random subset of 130 respondents, asking them whether they engaged in a variety of protest behaviors. We then regressed protest behavior on predicted scores from our protest intentions models. We find a significant effect: a ten-point increase in intention to protest is associated with a .30 increase in the odds of reporting a protest six months later. This provides strong evidence of the predictive validity of our research design (see Appendix C for details).

Fourth, our specification of mediation —in which likelihood of success mediates some of the effects of vignette dimensions on intention to protest—-does not parallel the causal interpretation of our vignette dimensions, because likelihood of success is endogenous (see Appendix B). In our design, the total effect of vignette dimensions on likelihood of success and intention to protest are causal, but the direct effect of success on intentions requires the assumption of ignorability conditional on covariates to be viewed as causal. Future research might explore the introduction of an instrumental variable for likelihood of success, paralleling the classic “encouragement design” (Bullock et al. 2010).

Fifth, we should also note that preventing a tuition increase approximates a pure public good for undergraduate students, as it is non-excludable (all students benefit) and non-rivalrous (the saving by one student does not affect the saving by others). Our results would be expected 
to differ for common-pool resources (rivalrous) — which Olson assumes_-and club goods (exclusive). For common goods with rivalrous consumption, group size may be negatively correlated with collective action. In that case, rational students should protest only when the student body is relatively small. Research empirically investigating the impact of (non)rivalrous and (non)excludable goods on the dynamics of protest would be a welcome addition to the collective action literature.

Finally, the present study focused on student protest, an important example of collective action and a pivotal event in the generation of student social movements. To what extent do our results generalize to other forms of collective action and social movements? Social movement scholars have distinguished social movements on various dimensions, including local versus global scope, reform versus radical objective, group versus individual target, peaceful versus violent method, and new versus ongoing grievance. Our study of student protests against tuition increases falls under conditions of local scope, reformist objective, group (university administration) target, peaceful methods, and a newly-imposed grievance. Moreover, our results are conditional on a local population at risk, relatively available social networks, common interests, and clear source of grievance. Therefore, the scope of our results is relevant to labor organizing and labor protests, and less so to nationwide political campaigns, spontaneous riots, and non-institutional mobilization. We therefore welcome future research that explores whether our results can explain such disparate examples of collective action. 


\section{References}

Akerlof, George A. and Rachel E. Kranton. 2000. "Economics and Identity.” The Quarterly Journal of Economics 115: 715-753.

Alexander, Cheryl S. and Henry J. Becker. 1978. “The Use of Vignettes in Survey Research.” Public Opinion Quarterly 42: 93-104.

Atkinson, John W. “Motivational Determinants of Risk-Taking Behavior.” Psychological Review 64:359-72.

Auspurg, Katrin and Thomas Hinz. 2014. Factorial Survey Experiments. New York, NY: Sage Publications.

Auspurg, Katrin and Annette Jäckle. 2017. “First Equals Most Important? Order Effects in Vignette-Based Measurement.” Sociological Methods \& Research 46: 490-539.

Bem, Daryl J. and Charles G Lord. 1979. “Template-Matching: A Proposal for Probing the Ecological Validity of Experimental Settings in Social Psychology.” Journal of Personality and Social Psychology 37: 833-846.

Benford, Robert D. and David A. Snow. 2000. "Framing Processes and Social Movements: An Overview and Assessment.” Annual Review of Sociology 26: 611-39.

Andrews, Kenneth T. and Michael Biggs. 2006. “The Dynamics of Protest Diffusion: Movement Organizations, Social Networks, and News Media in the 1960 Sit-Ins.” American Sociological Review 71: 752-777.

Bergstrand, Kelly. 2014. “The Mobilizing Power of Grievances: Applying Loss Aversion and Omission Bias to Social Movements.” Mobilization: An International Quarterly 19: 123142. 
Bullock, John G., Donald P. Green, and Shang E. Ha. 2010. “Yes, But What’s the Mechanism? (Don’t Expect an Easy Answer).” Journal of Personality and Social Psychology 98: 550558.

Byman, Daniel. 2016. “’Death Solves All Problems’: The Authoritarian Model of Counterinsurency.” Journal of Strategic Studies 39/1: 62-93.

Calhoun, Craig. 1991. “The Problem of Identity in Collective Action.” Pp. 51-75 in MacroMicro Linkages in Sociology. Newark Park, CA: Sage Publications.

Centola, Damon M. 2013. “Homophily, Networks, and Critical Mass: Solving the Start-Up Problem in Large Group Collective Action.” Rationality \& Society 25:3-40.

Chesher, Andrew and Margaret Irish. 1987. "Residual Analysis in the Grouped and Censored Normal Linear Model” Journal of Econometrics 34:33-61.

Chong, Dennis. 1991. Collective Action and the Civil Rights Movement. Chicago, IL: University of Chicago Press.

Coleman, James. 1990. Foundations of Social Theory. Cambridge, MA: Harvard University Press.

College Board. 2014. Trends in College Pricing. New York: The College Board. Collins, Randall. 2005. Interaction Ritual Chains. Princeton, NJ: Princeton University Press. Cragg, John G. 1971. “Some Statistical Models for Limited Dependent Variables with Application to the Demand for Durable Goods.” Econometrica 39:829-844.

Crossley, Nick. 2008. "Social Networks and Student Activism: On the Politicising Effect of Campus Connections.” The Sociological Review 56: 596-612.

Crossley, Nick and Joseph Ibrahim. 2012. “Critical Mass, Social Networks and Collective Action: Exploring Student Political Worlds.” Sociology 46: 596-612.

DeGroot, Gerard J. (ed). 1998. Student Protest: The Sixties and After. London: Longman. 
Dülmer, Hermann. 2015. “The Factorial Survey: Design Selection and its Impact on Reliability and Internal Validity.” Sociological Methods and Research 45:304-47.

Edwards, Ward. 1954. “The Theory of Decision-Making.” Psychological Bulletin 51:380-417.

Feather, Norman T. 1957. "Subjective Probability and Decision under Uncertainty. Psychological Review 66:150-64

Fehr, Ernst and Herbert Gintis. 2007. "Human Motivation and Social Cooperation: Experimental and Analytical Foundations.” Annual Review of Sociology 33: 43-64.

Fillieule, Oliver. 2012. “The Independent Psychological Effects of Participation in Demonstrations.” Mobilization: An International Quarterly. 17:235-248.

Finkel, Steven E., and Edward N. Muller. 1998. "Rational Choice and the Dynamics of Collective Political Action: Evaluating Alternative Models with Panel Data.” The American Political Science Review 92:37-49.

Finkel, Steven E., Edward N. Muller, and Karl-Dieter Opp. 1989. “Personal Influence, Collective Rationality, and Mass Political Action.” The American Political Science Review 83:885-903.

Fishbein, Martin, and Icek Ajzen. 1975. Belief, Attitude, Intention and Behavior: An Introduction to Theory and Research. Reading, MA: Addison Wesley

Francisco, Ronald A. 2010. Collective Action Theory and Empirical Evidence. New York, NY: Springer.

Gamson, William A. 1990. The Strategy of Social Protest. Belmont, CA: Wadsworth. Glaeser, Edward L., Bruce Sacerdote, José A. Scheinkman. 1996. “Crime and Social Interactions.” The Quarterly Journal of Economics 111: 507-548.

Gould, Roger. 1991. "Multiple Networks and Mobilization in the Paris Commune, 1871.” American Sociological Review 56: 716-729. 
Gould, Roger. 1993. “Collective Action and Network Structure.” American Sociological Review 58: 182-196.

Granovetter, Mark. 1978. “Threshold Models of Collective Behavior.” American Journal of Sociology 83: 1420-43.

Grasso, Maria T. and Marco Giugni. 2016. "Protest Participation and Economic Crisis: The Conditioning Role of Political Opportunities.” European Journal of Political Research 55: 663680.

Greene, William H. 2003. Econometric Analysis. Upper Saddle River, NJ: Prentice Hall. Hainmueller, Jens, Dominik Hangartner, and Teppei Yamamoto. 2015. “Validating Vignette and Conjoint Survey Experiments against Real-World Behavior.” Proceedings of the National Academy of Sciences 112: 2395-2400.

Hardin, Russell. 1982. Collective Action. Baltimore, MD: Johns Hopkins University Press. Hayes, Andrew F. 2013. Introduction to Mediation, Moderation, and Conditional Process Analysis: A Regression-Based Approach. New York: The Guilford Press.

Hechter, Michael and Satoshi Kanazawa. 1997. "Sociological Rational Choice Theory.” Annual Review of Sociology 23:191-214.

Hechter, Michael, Steven Pfaff, and Patrick Underwood. 2016. “Grievances and the Genesis of Rebellion: Mutiny in the Royal Navy, 1740-1820.” American Sociological Review 81: 165-189.

Heckathorn, Douglas D. 1996. “The Dynamics and Dilemmas of Collective Action.” American Sociological Review 61: 250-277.

Hensby, Alexander. 2017. “Campaigning for a Movement: Collective Identity and Student Solidarity in the 2010/11 UK Protests against Fees and Cuts. Pp. 13-30 in Student Politics and Protest: International Perspectives, edited by R. Brooks. London: Routledge. 
Hirsch, Eric L. 1990. “Sacrifice for the Cause: Group Processes, Recruitment, and Commitment in a Student Social Movement.” American Sociological Review 55: 243-254.

Holland, Paul. 1988. “Causal Inference and Path Analysis.” Pp. 449-484 in Sociological Methodology, 1988. Edited by C.C. Clogg. Washington, DC: American Sociological Association.

Houle, Jason. 2014. “Disparities in Debt: Parent’s Socioeconomic Resources and Young Adult Student Loan Debt.” Sociology of Education 87: 53-69.

Isaac, R. Mark and James M. Walker. 1988. “Group Size Effects in Public Goods Provision: The Voluntary Contributions Mechanism. The Quarterly Journal of Economics 103:177199.

Jasso, Guillermina. 2006. “Factorial Survey Methods for Studying Beliefs and Judgments.” Sociological Methods \& Research 34: 334-423.

Jasso, Guillermina and Karl Dieter-Opp. 1997. "Probing the Character of Norms: A Factorial Survey Analysis of the Norms of Political Action.” American Sociological Review 62: 947-964.

Jasso, Guillermina and Peter H. Rossi. 1977. “'Distributive Justice and Earned Income.’’ American Sociological Review 42:639-51.

Jenkins, Craig. 1983. "Resource Mobilization Theory and the Study of Social Movements.” Annual Review of Sociology 9:527-533.

Johnston, Angus. 2015. “Student Protests, Then and Now: From 'Hey, Hey, LBJ’ to ‘Black Lives Matter'”. Chronicle of Higher Education, Section B, December 18.

Kahneman, Daniel. 2011. Thinking, Fast and Slow. New York, NY: Farrar, Straus and Giroux. Kim, Hyojoung and Peter S. Bearman. 1997. "The Structure and Dynamics of Movement Participation.” American Sociological Review 62: 70-93. 
Kitts, James A. 2000. “Mobilizing in Black Boxes: Social Networks and Participation in Social Movement Organizations.” Mobilization: An International Journal 5: 241-257.

Klandermans, Bert. 1984. "Mobilization and Participation: Social-Psychological Explanations of Resource Mobilization Theory.” American Sociological Review 49: 583-600.

Klandermans, Bert. 1997. The Social Psychology of Protest. Oxford: Blackwell.

Kollock, Peter. 1998. "Social Dilemmas: The Anatomy of Cooperation.” Annual Review of Sociology 24: 183-214.

Ledyard, John O. 1995. “Public Goods: A Survey of Experimental Research.” In The Handbook of Experimental Economics, pp. 111-194. Princeton, NJ: Princeton University Press.

Levi, Margaret and April Linton. 2003. "Fair Trade: A Cup at a Time?” Politics \& Society 31: 407-432.

Lewin, Kurt, Tamara Dembo, Leon Festinger, and Pauline S. Sears. 1944. "Level of Aspirations. Pp. 333-378 in Personality and the Behavior Disorders, edited by J.M. Hunt. Oxford, UK: Ronald Press.

Lichbach, Mark. 1995. The Rebel’s Dilemma. Ann Arbor, MI: University of Michigan Press

Liebrand, Wim B.G. 1986. “The Ubiquity of Social Values in Social Dilemmas.” Pp. 113-133 in Experimental Studies of Social Dilemmas, edited by Henk Wilke, Christel Rutte, and David Messick. Frankfurt: Peter Lang Publishing Company.

Lim, Chaeyoon. 2008. "Social Networks and Political Participation: How Do Networks Matter?” Social Forces 87: 961-982.

Lohmann, Susanne. 1994. "The Dynamics of Informational Cascades: The Monday Demonstrations in Leipzig, East Germany, 1989-91.” World Politics 47: 42-101. Lopez-Pintado, Dunia and Duncan Watts. 2008. “Social Influence, Binary Decisions, and Collective Dynamics.” Rationality \& Society 20: 399-443. 
Macy, Michael. 1990. “Learning-Theory and the Logic of Critical Mass.” American Sociological Review 53: 809-826.

Macy, Michael. 1991. “Chains of Cooperation: Threshold Effects in Collective Action.” American Sociological Review 56: 730-747.

Manski, Charles F. 1990. “The Use of Intentions Data to Predict Behavior: A Best-Case Analysis.” Journal of the American Statistical Association 85:934-940.

Marwell, Gerald and Pamela Oliver. 1993. The Critical Mass in Collective Action: A MicroSocial Theory. Cambridge, UK: Cambridge University Press.

Matsueda, Ross L. 2012. “Key Advance in the History of Structural Equation Modeling.” Pp. 17-42 in Handbook of Structural Equation Modeling. Edited by R.H. Hoyle. New York, NY: Guilford.

McAdam, Doug. 1988. Freedom Summer. New York: Oxford University Press.

McCarthy, John D., and Mayer N. Zald. 1977. "Resource Mobilization and Social Movements:

A Partial Theory.” American Journal of Sociology 82:1212-1241.

McCarthy, John D., Mark Wolfson, David P. Baker, and Elaine Mosakowski. 1988. “The Founding of Social Movement Organizations: Local Citizens’ Groups Opposing Drunken Driving.” Pp. 71-84 in Ecological Models of Organizations. Edited by G.R. Carroll. Ecological Models of Organizations. Cambridge, MA: Ballinger.

McCarthy, John D., Patrick Rafail, Clark McPhail, Andrew W. Martin, and Edward T. Walker. Forthcoming. "Issueless Campus Riots: Toward a Structural Account of Disorderly Gatherings, 1997-2007.” Social Forces.

McCormick, Richard P. 1990. The Black Student Protest Movement at Rutgers. New Brunswick: Rutgers University. 
McGloin, Jean Marie, and Kyle J. Thomas. 2016. “Incentives for Collective Deviance, Group Size, and Changes in Perceived Risk, Cost, and Reward.” Criminology 54:459-86

McVeigh, Rory. 2009. The Rise of the Ku Klux Klan: Right-Wing Movements and National Politics. Minneapolis, MN: University of Minnesota Press.

Medina, Luis F. 2007. A Unified Theory of Collective Action and Social Change. Ann Arbor, MI: University of Michigan Press.

Mehreen, Rushida, and Ryan Thomson. 2017. “Affinities and Barricades: A Comparative Analysis of Students Organizing in Quebec and the USA.” Pp. 63-80 in Student Politics and Protest: International Perspectives. London: Routledge.

Morgan, Stephen L. and Christopher Winship. 2007. Counterfactuals and Causal Inference: Methods and Principles for Social Research. Cambridge, MA: Cambridge University Press. Muller, Edward, Henry A. Dietz, and Steven E. Finkel. 1991. “Discontent and the Expected Value of Rebellion: The Case of Peru.” American Political Science Review 85: 1261-1282. Murphy, Gillian and Steven Pfaff. 2005. “Thinking Locally, Acting Globally? What the Seattle WTO-Protests Tell Us About the Global Justice Movement.” Political Power \& Social Theory 17: 151-176.

Nelson, Thomas E., Oxley, Zoe, and Clawson, Rosalee A. 1997. "Toward a Psychology of Framing Effects." Political Behavior 19: 221-46.

Oberschall, Anthony. 1973. Social Conflict and Social Movements. Englewood Cliffs, NJ: Prentice Hall.

Oberschall, Anthony. 1980. "Loosely Structured Collective Conflict: A Theory and an Application.” Research in Social movements, Conflict and Change 3:45-68.

Oberschall, Anthony. 1994. "Rational Choice in Collective Protests.” Rationality \& Society 6: 79-100. 
Oliver, Pamela. 1980. "Rewards and Punishments as Selective Incentives for Collective Action.” American Journal of Sociology 65:1356-1375.

Oliver, Pamela, and Gerald Marwell. 1988. “The Paradox of Group Size in Collective Action.” American Sociological Review 53:1-8.

Oliver, Pamela E., and Gerald Marwell. 2001. "Whatever Happened to Critical Mass Theory? A Retrospective and Assessment.” Sociological Theory 19:292-311.

Oliver, Pamela, Gerald Marwell, and Ruy Teixeria. 1985. “A Theory of Critical Mass. I. Interdependence, Group Heterogeneity, and the Production of Collective Action.” American Journal of Sociology 91: 522-56.

Olson, Mancur. 1965. The Logic of Collective Action: Public Goods and the Theory of Groups. Cambridge, MA: Harvard University Press.

Opp, Karl-Dieter. 1988. “Grievances and Participation in Social Movements.” American Sociological Review 53:853-864.

Opp, Karl-Dieter. 1989. The Rationality of Political Protest: A Comparative Analysis of Rational Choice Theory. Boulder, CO: Westview.

Opp, Karl-Dieter. 1999. “Contending Conceptions of the Theory of Rational Action.” Journal of Theoretical Politics 11: 171-202.

Opp, Karl-Dieter. 2009. Theories of Social Protest and Social Movements: A Multidisciplinary Introduction, Critique, and Synthesis. New York, NY: Routledge.

Opp, Karl-Dieter and Christiane Gern. 1993. “Dissident Groups, Personal Networks, and Spontaneous Cooperation: The East German Revolution of 1989.” American Sociological Review 58: 659-680.

Opp, Karl-Dieter, Christiane Gern, and Peter Voss. 1996. Origins of a Spontaneous Revolution: East Germany, 1989. University of Michigan Press. 
Pagan, Adrian, and Frank Vella. 1989. “Diagnostic Tests for Models Based on Individual Data: A Survey.” Journal of Applied Econometrics 4: S29-S59.

Pfaff, Steven. 1996. “Collective Identity and Informal Groups in Revolutionary Mobilization: East Germany in 1989.” Social Forces 75/1: 91-117.

Pfaff, Steven and Michel Hechter. 2020. The Genesis of Rebellion: Governance, Grievance, and Mutiny in the Age of Sail. Cambridge, UK: Cambridge University Press.

Polletta, Francesa and James M. Jasper. 2001. "Collective Identity and Social Movements.” Annual Review of Sociology 27: 283-305.

Rasler, Karen. 1996. “Concessions, Repression, and Political Protest in the Iranian Revolution.” American Sociological Review 61: 132-152.

Raudenbush, Stephen and Anthony S. Bryk. 2002. Hierarchical Linear Models: Applications and Data Analysis. Newbury Park, CA: Sage.

Robbins, Blaine and Edgar Kiser. 2018. "Legitimate Authorities and Rational Taxpayers: An Investigation of Voluntary Compliance and Method Effects in a Survey Experiment of Income Tax Evasion.” Rationality \& Society 30: 247-301.

Robbins, Blaine G., Ross L. Matsueda, and Steven J. Pfaff. Forthcoming. “Mapping the Production and Mobilization Functions of Collective Action.” Socius.

Rossi, Peter H. and Steven Nock. 1982. Measuring Social Judgments: The Factorial Survey Approach. Beverly Hills: Sage Publications.

Sampson, Robert J., Doug McAdam, Heather MacIndoe, and Simon Weffer-Elizondo. 2005.

“Civil Society Reconsidered: The Durable Nature and Community Structure of Collective Civic Action.” American Journal of Sociology 111: 673-714.

Sauer, Carsten, Katrin Auspurg, Thomas Hinz, and Stefan Liebig. 2011. "The Application of Factorial Surveys in General Population Samples: The Effects of Respondent Age and 
Education on Response Times and Response Consistency.” Survey Research Methods 5: 89-102.

Schelling, Thomas. 1971. “Dynamic Models of Segregation.” Journal of Mathematical Sociology 1:143-186.

Schussman, Alan and Sarah A. Soule. 2005. "Process and Protest: Accounting for Individual Protest Participation.” Social Forces 84: 1083-1108.

Schwarzer, R., and M. Jerusalem. 1995. “Generalized Self-Efficacy Scale.” In J. Weinman, S. Wright, and M. Johnston, Measures in Health Psychology: A User's Portfolio. Causal and Control Beliefs (pp. 35-37). Windsor, England: NFER-NELSON.

Simpson, Brent. 2004. “Social Values, Subjective Transformations, and Cooperation in Social Dilemmas.” Social Psychology Quarterly 67: 385-95.

Simpson, Brent and Robb Willer. 2008. “Altruism and Indirect Reciprocity: An Interaction of Person and Situation in Prosocial Behavior.” Social Psychology Quarterly 71: 37-52. Snow, David A. and Robert D. Benford. 1988. “Ideology, Frame Resonance, and Participant Mobilization.” International Social Movement Research 1:197-218.

Snow, David A. and Pamela Oliver. 1995. "Social Movements and Collective Behavior: Social Psychological Considerations.” Pp. 571-599 in Sociological Perspectives on Social Psychology. Edited by K.S. Cook, G.A. Fine, and J. House. Boston: Allyn and Bacon. Snow, David A., E. Burke Rochford, Jr., Steven K. Worden, and Robert D. Benford. 1986. “Frame Alignment Processes, Micromobilization and Movement Participation.” American Sociological Review 51:464-481.

Snow, David A., Louis A. Zurcher, Jr., and Sheldon Ekland-Olson. 1980. “Social Networks and Social Movements: A Microstructural Approach to Differential Recruitment.” American Sociological Review 45: 787-801. 
Sobel, Michael E. 1982. “Asymptotic Confidence Intervals for Indirect Effects in Structural Equation Models.” Pp. 290-312 in Sociological Methodology 1982. Edited by S. Leinhardt. San Francisco, CA: Jossey-Bass.

Sobel, Michael E. 2008. "Identification of Causal Parameters in Randomized Studies with Mediating Variables.” Journal of Educational and Behavioral Statistics 33:230-51.

Soule, Sarah A. 1997. “The Student Divestment Movement in the United States and Tactical Diffusion: The Shantytown Protest.” Social Forces 75: 855-882.

Stets, Jan E. and Peter J. Burke. 2000. “Identity Theory and Social Identity Theory.” Social Psychology Quarterly 63: 224-237.

Tajfel, Henri. 1981. Human Groups and Social Categories: Studies in Social Psychology. Cambridge: Cambridge University Press.

Tausch, Nicole, Julia C. Becker, Russell Spears, Oliver Christ, Rim Saab, Purnima Singh and Roomana N. Siddiqui. 2011. “Explaining Radical Group Behavior: Developing Emotion and Efficacy Routes to Normative and Nonnormative Collective Action.” Journal of Personality and Social Psychology 101: 129-148.

Tillock, Harriet and Denton E. Morrison. 1979. “Group Size and Contributions to Collective Action: An Examination of Olson’s Theory Using Data from Zero Population Growth.” Research in Social Movements, Conflicts and Change 2:131-158.

Valdez, Sarah. 2011. "Subsidizing the Cost of Collective Action: International Organizations and Protest among Polish Farmers during Democratic Transition.” Social Forces 90: 475495.

Van Dyke, Nella. 1998. “Hotbeds of Activism: Locations of Student Protest.” Social Problems 45: 205-220. 
Van Dyke, Nella, Marc Dixon, and Helen Carlon. 1997. “Manufacturing Dissent: Labor Revitalization, Union Summer and Student Protest.” Social Forces 86: 193-214.

Van Lange, Paul A. M. 1999. “The Pursuit of Joint Outcomes and Equality in Outcomes: An Integrative Model of Social Value Orientation.” Journal of Personality and Social Psychology 77: 337-349.

Van Lange, Paul A. M., Wilma Otten, Ellen M. N. De Bruin and Jeffrey A. Joireman. 1997. “Development of Prosocial, Individualistic, and Competitive Orientations: Theory and Preliminary Evidence.” Journal of Personality and Social Psychology 73: 733-746.

Van Zomeren, Martijn, Russell Spears, Agneta H. Fischer, and Colin Wayne Leach. 2004. "Put Your Money Where Your Mouth Is! Explaining Collective Action Tendencies Through Group-Based Anger and Group Efficacy.” Journal of Personality and Social Psychology 87: 649-664.

Van Zomeren, Martijn, Tom Postmas and Russell Spears. 2008. “Toward an Integrative Social Identity Model of Collective Action: A Quantitative Research Synthesis of Three SocioPsychological Perspectives.” Psychological Bulletin 134: 503-535.

Wallander, Lisa. 2009. “'25 Years of Factorial Surveys in Sociology: A Review.’ Social Science Research 38: 505-20.

Werner, Paul. 1978. “Personality and Attitude-Activism Correspondence.” Journal of Personality and Social Psychology 36:1375-1390.

Willer, Robb. 2009. “Groups Reward Individual Sacrifice: The Status Solution to the Collective Action Problem.” American Sociological Review 74: 23-43.

Wood, James L. 1998. “’With a Little Help from our Friends’: Student Activism and the 1992 Crisis at San Diego State University.” Pp. 264-279 in Student Protest: The Sixties and After, edited by G.J. DeGroot. London: Longman. 
Wood, Lesley. 2014. Crisis and Control: The Militarization of Protest Policing. Pluto Press.

Zald, Mayer N. and John D. McCarthy. 1979. The Dynamics of Social Movements: Resource Mobilization, Social Control, and Tactics. Cambridge, MA: Winthrop Publishers.

Zhao, Dingxin. 1998. “Ecologies of Social Movements: Student Mobilization during the 1989 Prodemocracy Movement in Beijing.” American Journal of Sociology 103: 1493-1529.

Zhao, Dingxin. 2000. "State-Society Relations and the Discourses and Activities of the 1989 Beijing Student Movement.” American Journal of Sociology 105: 1592-1632. 
Table 1. Sample Descriptive Statistics

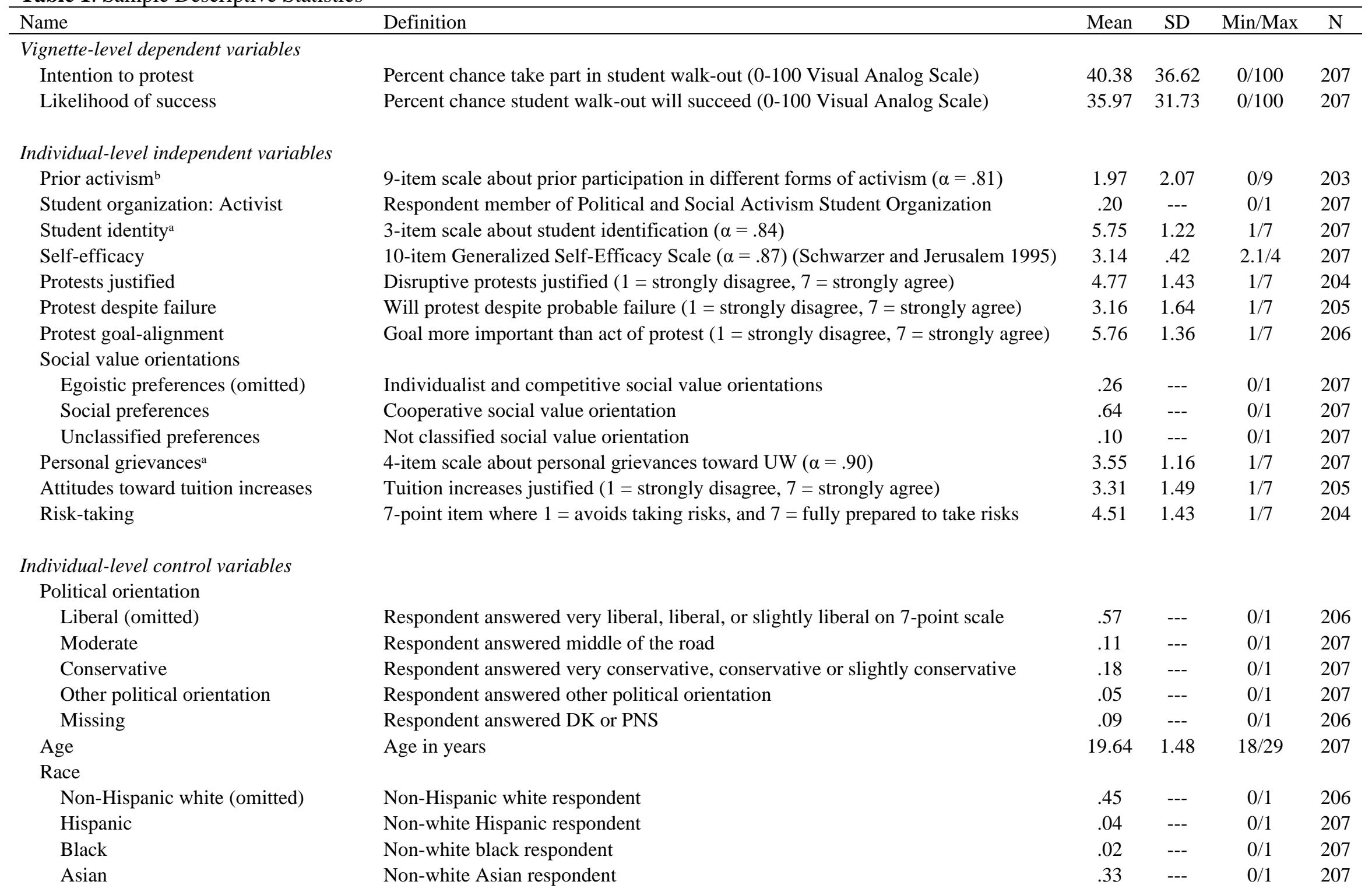




\begin{tabular}{|c|c|c|c|c|c|}
\hline Other race & Other race & .12 & --- & $0 / 1$ & 207 \\
\hline Missing & Race and ethnicity is DK or PNS & .04 & --- & $0 / 1$ & 207 \\
\hline \multicolumn{6}{|l|}{ Gender } \\
\hline Female (omitted) & Female respondent & .50 & --- & $0 / 1$ & 206 \\
\hline Male & Male respondent & .50 & --- & $0 / 1$ & 206 \\
\hline \multicolumn{6}{|l|}{ Economic dependence } \\
\hline Financial dependence (omitted) & For purposes of financial aid, respondent is financially dependent & .70 & --- & $0 / 1$ & 206 \\
\hline Financial independence & For purposes of financial aid, respondent is financially independent & .15 & --- & $0 / 1$ & 206 \\
\hline Missing & For purposes of financial aid, respondent is DK & .15 & --- & $0 / 1$ & 206 \\
\hline \multicolumn{6}{|l|}{ Residency } \\
\hline In-state (omitted) & University recognizes respondent as an in-state student & .78 & --- & $0 / 1$ & 207 \\
\hline Out-of-state & University recognizes respondent as an out-of-state student & .13 & --- & $0 / 1$ & 207 \\
\hline International & University recognizes respondent as an international student & .09 & --- & $0 / 1$ & 207 \\
\hline
\end{tabular}

${ }^{1} \mathrm{DK}=$ don't know; PNS = prefer not to say; ${ }^{\mathrm{a}}=$ row means of the items were used, ignoring missing values; ${ }^{\mathrm{b}}=$ row sums of the items were used, treating

missing values as zero or as missing if all items were missing.

${ }^{2}$ The social values orientations construct consists of nine hypothetical decision scenarios, where participants decided for each scenario how to divide resources between themselves and a hypothetical "other". Each scenario included three options corresponding to one of three social values: a cooperative choice, which maximized joint gain; an individualist choice, which maximized personal gain without regard to the other's outcome; and a competitive choice, which maximized the difference between gains to self and other. Participants were classified as cooperative, individualist, or competitive if they made six or more choices corresponding to one of the social value orientations. Importantly, the ecological validity (Bem and Lord 1979), temporal stability (Van Lange 1999), and predictive power (Liebrand 1986) of these measures have been established. 
Table 2. Two-Level Tobit Models of Likelihood of Success and Intention to Protest, Individual-Level Total Effects

\begin{tabular}{|c|c|c|}
\hline & $\begin{array}{c}\text { Likelihood of Success } \\
\text { Coefficient (SE) }\end{array}$ & $\begin{array}{c}\text { Intention to Protest } \\
\text { Coefficient (SE) }\end{array}$ \\
\hline \multicolumn{3}{|l|}{ Controls } \\
\hline \multicolumn{3}{|l|}{ Political orientation } \\
\hline \multicolumn{3}{|l|}{ Liberal (omitted) } \\
\hline Moderate & $-5.33(4.60)$ & $-12.18 *(5.33)$ \\
\hline Conservative & $-4.27(3.17)$ & $-1.19(4.49)$ \\
\hline Other & $-7.31(5.00)$ & $-8.01(11.02)$ \\
\hline Missing & $-7.37(5.94)$ & $-9.57(9.58)$ \\
\hline Age & $1.99 *(0.82)$ & $0.36(1.18)$ \\
\hline \multicolumn{3}{|l|}{ Race } \\
\hline \multicolumn{3}{|l|}{ Non-Hispanic white (omitted) } \\
\hline Hispanic & $12.23 \dagger(6.76)$ & $21.08 *(8.76)$ \\
\hline Black & $-15.11(9.83)$ & $-4.41(7.46)$ \\
\hline Asian & $4.04(2.88)$ & $6.91(4.14)$ \\
\hline Other race & $-5.62(4.42)$ & $4.72(4.94)$ \\
\hline Missing & $-5.45(3.88)$ & $1.19(10.66)$ \\
\hline \multicolumn{3}{|l|}{ Gender } \\
\hline \multicolumn{3}{|l|}{ Female (omitted) } \\
\hline Male & $1.16(2.29)$ & $4.25(3.27)$ \\
\hline \multicolumn{3}{|l|}{ Economic dependence } \\
\hline \multicolumn{3}{|l|}{ Financial dependence (omitted) } \\
\hline Financial independence & $7.77 *(3.53)$ & $11.84 *(5.23)$ \\
\hline Missing & $0.35(2.93)$ & 2.25 (3.99) \\
\hline \multicolumn{3}{|l|}{ Residency } \\
\hline \multicolumn{3}{|l|}{ In-state (omitted) } \\
\hline Out-of-state & $-0.07(3.41)$ & $3.04(4.40)$ \\
\hline International & $8.41(5.44)$ & $5.89(6.45)$ \\
\hline \multicolumn{3}{|l|}{ Identity } \\
\hline Student organization: Activist & $0.19(3.02)$ & $4.02(4.37)$ \\
\hline Student identity & $-1.14(1.06)$ & $-0.42(1.50)$ \\
\hline Self-efficacy & $3.20(3.27)$ & $3.74(4.19)$ \\
\hline \multicolumn{3}{|l|}{ Previous Protest Participation } \\
\hline Prior activism & $0.31(0.66)$ & $0.60(0.91)$ \\
\hline \multicolumn{3}{|l|}{ Grievance and Protest Attitudes } \\
\hline Protests justified & $2.47 * *(0.81)$ & $5.14^{* * *}(1.14)$ \\
\hline Protest despite failure & $3.49 * * *(0.85)$ & $6.27 * * *(1.18)$ \\
\hline Protest goal-alignment & $0.68(0.92)$ & $-1.83(1.20)$ \\
\hline \multicolumn{3}{|l|}{ Social value orientations } \\
\hline \multicolumn{3}{|l|}{ Egoistic preferences (omitted) } \\
\hline Social preferences & $4.33(2.71)$ & $9.86^{* *}(3.72)$ \\
\hline Unclassified preferences & $6.72(4.26)$ & $9.43 *(4.58)$ \\
\hline Personal grievances & $-3.50 * *(1.12)$ & $-0.54(1.39)$ \\
\hline Attitudes toward tuition increases & $-0.25(0.85)$ & $-2.05 \dagger(1.11)$ \\
\hline \multicolumn{3}{|l|}{ Risk } \\
\hline Risk-taking & $4.23 * *(1.34)$ & $4.24 * *(1.34)$ \\
\hline
\end{tabular}




\begin{tabular}{lcc} 
Constant & $-52.09 * *(19.47)$ & $-54.36 \dagger(28.42)$ \\
Vignette-level variables & Yes & Yes \\
\hline $\operatorname{var}(v j)$ & & $326.92^{* * *}(59.22)$ \\
$\operatorname{var}(\varepsilon \mathrm{ij})$ & $176.16^{* * *}(27.10)$ & \\
$\operatorname{var}(\mathrm{vj})$ & $516.81^{* * *}(31.92)$ & \\
$\operatorname{var}(\delta \mathrm{ij})$ & 1940 & 1940 \\
Vignettes & 194 & 194 \\
Individuals & 258 & 368 \\
Left-censored observations & & 195 \\
Right-censored observations & &
\end{tabular}

*** $p<0.001,{ }^{* *} p<0.01, * p<0.05, \dagger p<0.10$ (two-tailed test)

Note: robust standard errors in parentheses (SE). Intention to protest left-censored at 0 and right-censored at 100; likelihood of success left-censored at 0 . 
Table 3. Two-Level Tobit Models of Likelihood of Success and Intention to Protest, Vignette-Level Total Effects

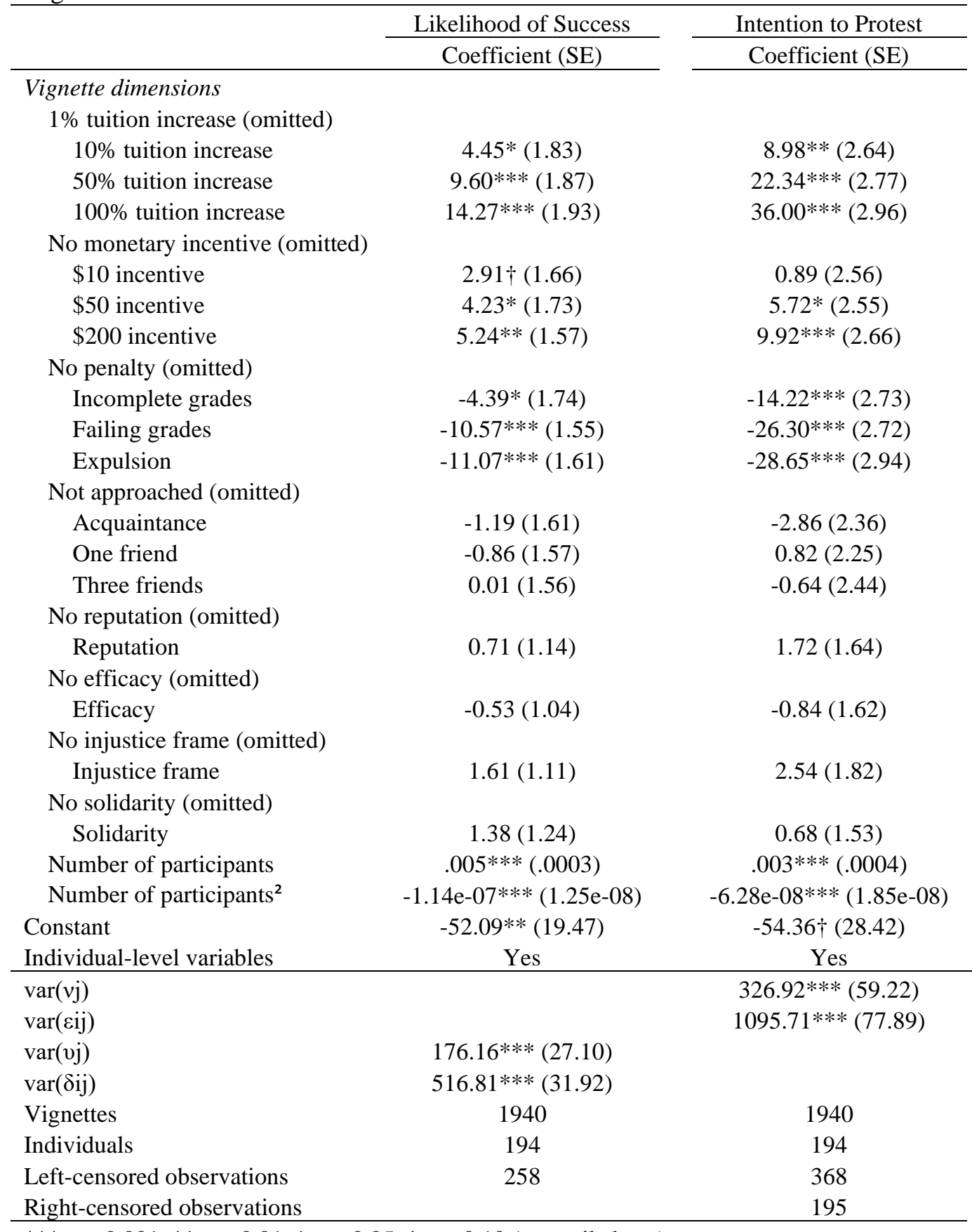

$* * * p<0.001,{ }^{* *} p<0.01,{ }^{*} p<0.05, \dagger p<0.10$ (two-tailed test)

Note: robust standard errors in parentheses (SE). Intention to protest left-censored at 0 and right-censored at 100; likelihood of success left-censored at 0 . 
Table 4. Total, Direct, and Indirect Effects of Vignette Characteristics on Intention to Protest

\begin{tabular}{|c|c|c|c|}
\hline Vignette characteristic & Total (SE) & Direct (SE) & Indirect (SE) \\
\hline \multicolumn{4}{|l|}{ Collective good } \\
\hline \multicolumn{4}{|c|}{$1 \%$ tuition increase (omitted) } \\
\hline $10 \%$ tuition increase & $9.36 * *(2.70)$ & $5.13 *(2.13)$ & $4.23 *(1.74)$ \\
\hline $50 \%$ tuition increase & $22.67 * * *(2.87)$ & $13.56 * * *(2.18)$ & $9.11^{* * *}(1.81)$ \\
\hline $100 \%$ tuition increase & $36.24^{* * *}(3.04)$ & $22.69 * * *(2.45)$ & $13.55^{* * *}(1.95)$ \\
\hline \multicolumn{4}{|l|}{ Selective rewards } \\
\hline \multicolumn{4}{|c|}{ No monetary incentive (omitted) } \\
\hline$\$ 10$ incentive & $1.17(2.63)$ & $-1.59(2.07)$ & $2.76 \dagger(1.57)$ \\
\hline$\$ 50$ incentive & $5.56 *(2.68)$ & $1.54(2.13)$ & $4.02 *(1.64)$ \\
\hline$\$ 200$ incentive & $9.94 * * *(2.73)$ & $4.97 *(2.21)$ & $4.97 * *(1.49)$ \\
\hline \multicolumn{4}{|l|}{ Selective punishments } \\
\hline \multicolumn{4}{|l|}{ No penalty (omitted) } \\
\hline Incomplete grades & $-14.76^{* * *}(2.81)$ & $-10.60 * * *(2.25)$ & $-4.16^{*}(1.66)$ \\
\hline Failing grades & $-26.52^{* * *}(2.71)$ & $-16.49 * * *(2.31)$ & $-10.03^{* * *}(1.55)$ \\
\hline Expulsion & $-29.09 * * *(3.00)$ & $-18.58 * * *(2.54)$ & $-10.51 * * *(1.56)$ \\
\hline Number of participants & $0.004^{* * *}(.0005)$ & $-0.001 *(.0004)$ & $0.005^{* * *}(0.0003)$ \\
\hline Number of participants ${ }^{2}$ & $-7.67 \mathrm{e}-08 * * *(1.88 \mathrm{e}-08)$ & $3.11 \mathrm{e}-08 *(1.51 \mathrm{e}-08)$ & $-1.08 \mathrm{e}-07 * * *(1.26 \mathrm{e}-08)$ \\
\hline
\end{tabular}

*** $p<0.001$, ** $p<0.01, * p<0.05, \dagger p<0.10$ (two-tailed test)

Note: normal-theory standard errors in parentheses (SE). 


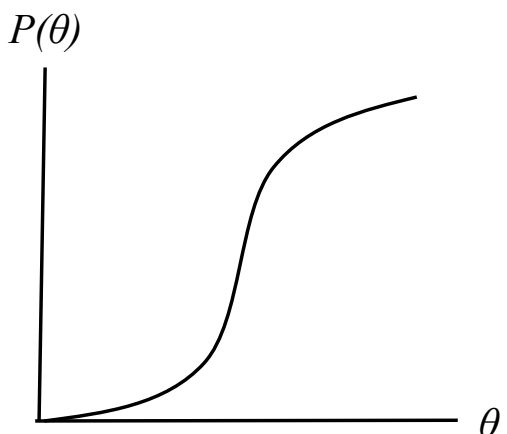

A. Third-Order Production Function
$P(\theta)$

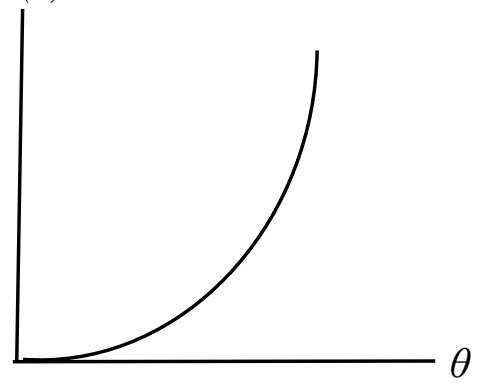

B. Accelerating Production Function:

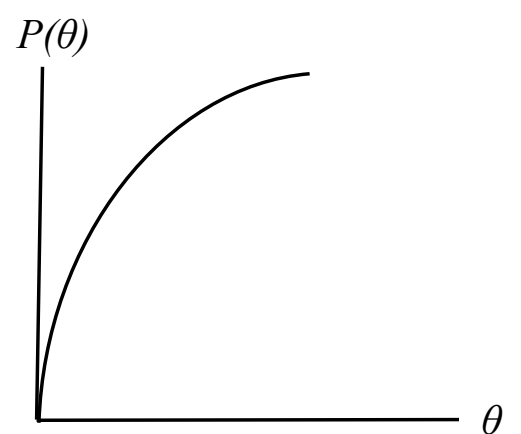

C. Decelerating Production Function

Figure 1. Shapes of Aggregate Production Functions for Collective Action 


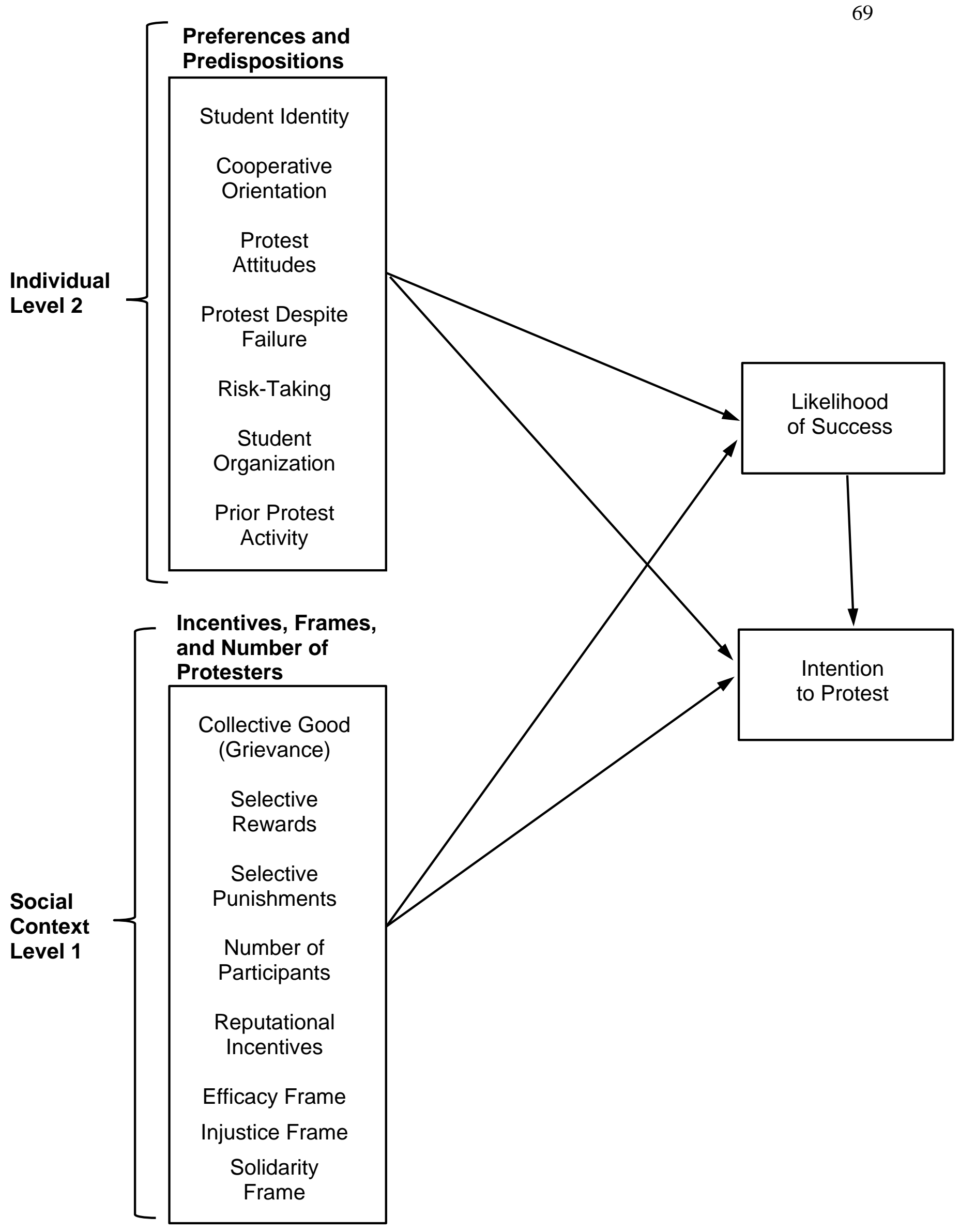

Figure 2. A Model of Willingness to Protest 


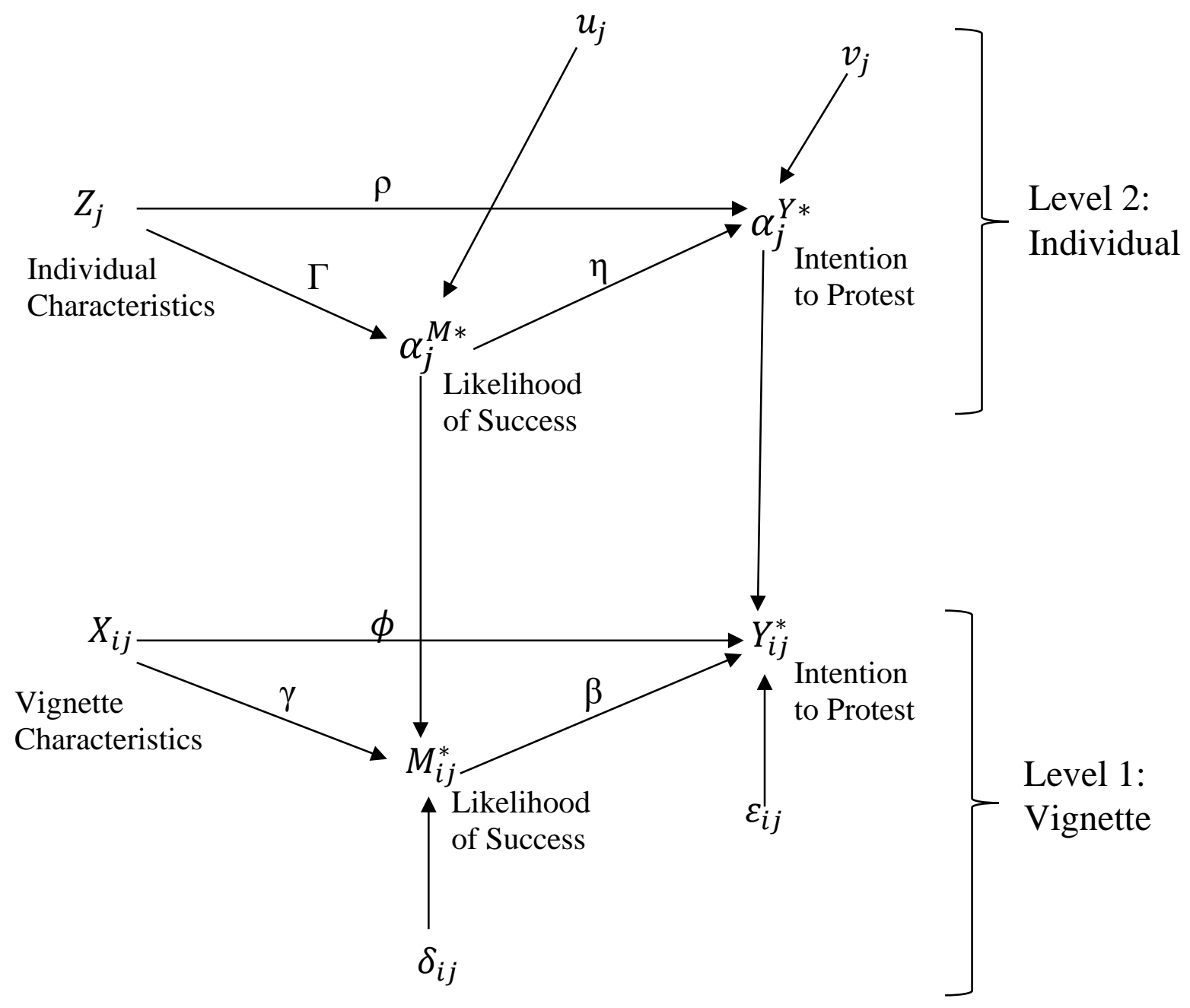

Figure 3. Path Diagram of a Two-Level Generalized Hierarchical Linear Structural Equation Model 

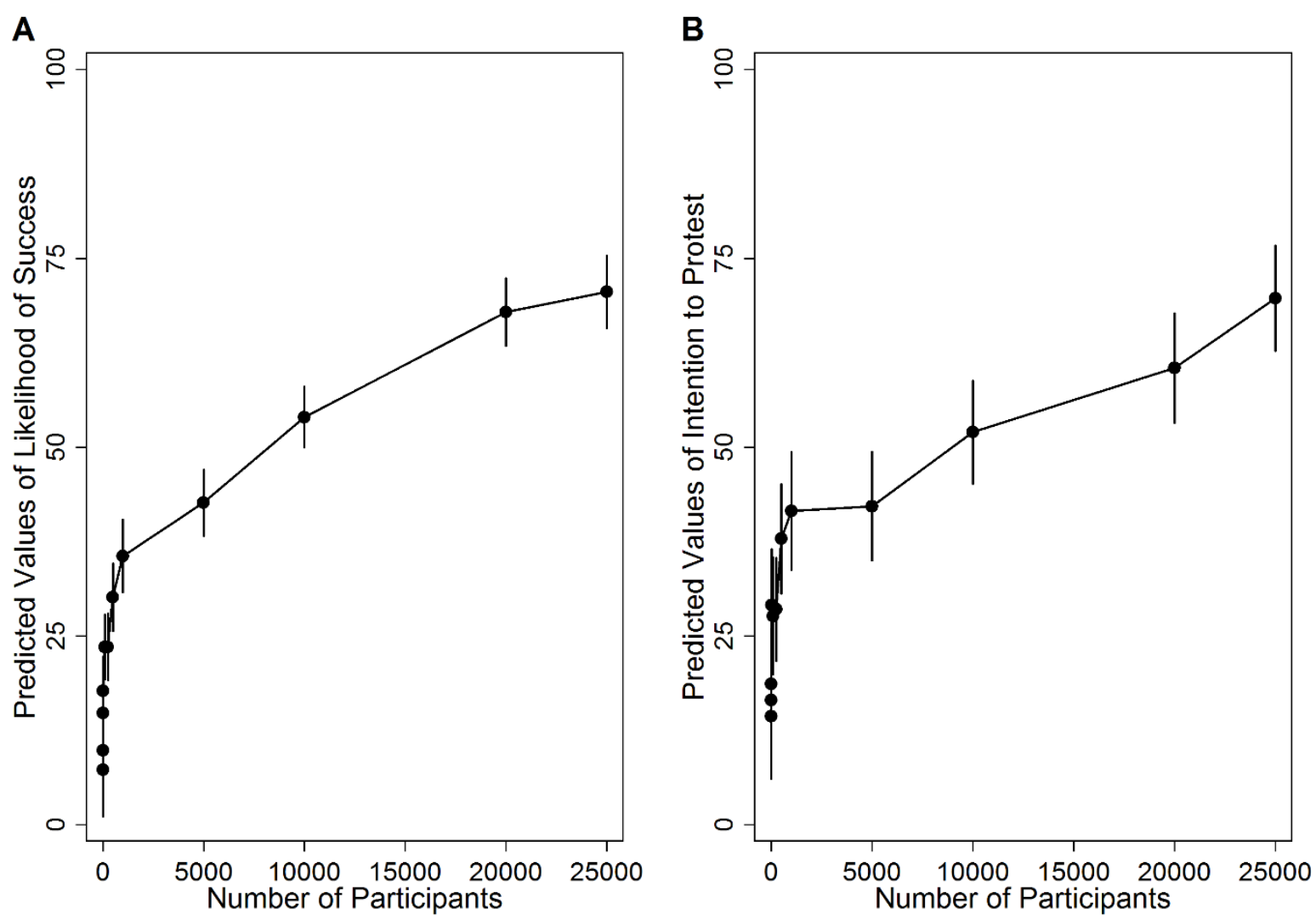

Figure 4. Graph of Predicted Likelihood of Success (Panel A) and Predicted Intention to Protest (Panel B) by Number of Participants (Dummies).

Note: Solid black markers indicate predicted values with $95 \%$ confidence intervals in black. 


\section{Appendix A}

Administration of the Factorial Survey and Description of Vignette Dimensions

\section{A. Administration of the Survey}

We contacted sampled participants over e-mail and invited them to participate in a webbased sociology study for a small payment. After consenting to participate, respondents were informed of the following hypothetical scenario:

"You are a college student enrolled at this University. The state legislature has just approved a tuition increase that will affect all students and will become effective at the beginning of the next academic quarter. The University administration supports the proposed increase in tuition. In response, a new student group has formed to oppose the tuition hike.

The student group is organizing students to take part in a walk-out during final exams week. The group's goal is to compel the administration and the state legislature to abandon the tuition hike. Students who participate in the walk-out agree not to take any exams or to turn in any papers or other graded work during the grading period. If the walk-out succeeds, no students will pay increased tuition.

The student group acknowledges that the walk-out will not be easy and wants to mobilize as many students as possible to help meet its goal. You have some concerns about the walk-out because it can only succeed if many students take part, but those who do not participate will enjoy the same benefit as those who do.”

We then told respondents that they would evaluate a series of hypothetical situations based on the background information provided above, and that each situation would end with two questions about the likelihood of success and the likelihood of participating in the student

protest. We then showed participants a series of ten vignettes randomly drawn with replacement from the vignette object universe of 49,152 unique vignettes, with an example vignette as follows:

"The proposed tuition hike will amount to a 50\% increase in the tuition you will pay (Collective Good). The University threatens that students who participate in the walk-out will receive failing grades in their courses (Selective Punishments). A national student federation will provide a $\$ 10$ debit card to every student who participates in the walk-out (Selective Rewards). 
A few days before the walk-out, three of your friends approach you and urge you to participate in the walk-out with them (Social Inducement). In conversing with your friends and family, the clear consensus among them is that they will admire anyone who takes part in the walk-out (Reputational Incentives). In the days before the walk-out is to begin, the student group declares that all students should unite behind the walk-out as solidarity is the only defense against social injustice (Solidarity Frame).

You do not know how student walk-outs have affected tuition hikes at other American universities (Efficacy Frame). The University's president and top administrators have announced that they are not going to adjust their salaries for the coming year (Injustice Frame). In the morning on the first day of the walk-out, you learn that five students (or $0.018 \%$ of 28,000 possible students) have participated in the walk-out (Number of Participants).”

Italicized descriptions of dimensions were not included in the vignette. After each vignette, we asked participants two questions: (1) "Given this set of conditions, what is the percent chance that the student walk-out will succeed?” (Likelihood of Success), and (2) “Given this set of conditions, what is the percent chance that you would take part in the student walk-out?” (Intention to Protest). Each question was structured as a probability ranging from 0 to 100 in the form of a visual analog scale with a slider bar.

B. Vignette Dimensions

Table A1 presents the exact wording and levels of our nine vignette dimensions.

\section{[Table A1 about here]}

C. Internal Validity of Vignettes

The internal validity of the vignette approach rests on the extent to which the scenarios realistically depict protest situations relevant to the theory being tested. The scenarios may include a mix of factual and counterfactual conditions, but together respondents must perceive them as realistic. Relatedly, respondents must perceive the levels of the vignette dimensions and consider those levels in their responses. Given our 
experimental design, in which levels of vignette dimensions are manipulated (i.e., randomly assigned) by the researcher, the treatment manipulations must be "successful.” In addition, the manipulation of vignette levels and presentation to respondents must be consistent with how such levels would appear in actual protest situations. Finally, vignettes must minimize social desirability and other response effects.

To ensure that our vignettes are realistic and manipulations worked in authentic ways, we designed initial scenarios to be consistent with previous vignette studies of general protests (e.g., Jasso and Opp 1997) and then modified the scenarios based on a series of focus groups and pretests. First, we pre-tested an early draft of the survey using all members of the research team, and modified the survey to increase realism. Second, we administered the modified survey to a dozen social science graduate students, half of whom had expertise in survey methods, and conducted a post-survey focus group session to receive criticisms and suggestions. After this illuminating session, we substantially revised our scenarios. Third, in administering the final survey, we asked respondents at the end of the survey to provide open-ended comments about their survey experience, including any concerns they had about the survey. Finally, we timed the length of each survey session as a further check of invalidity (such as answering too quickly, identically, or randomly). The survey took respondents an average of 31 minutes to complete. Respondents spent an average of three minutes to complete the first vignette, and less than one minute on each of the subsequent nine vignettes.

\section{Factorial Survey Experiments versus Conjoint Experiments}

An alternative method is the conjoint experiment, which simply lists vignette characteristics in a list, rather than embedding them in a narrative describing a concrete 
situation. The most recent and compelling use of the conjoint method was a design that mimicked a real-world situation in Switzerland, in which municipalities used referendums to decide which applications of foreign residents should be approved for immigration (Hainmueller et al. 2015). The referendum resembled a conjoint experiment, giving the characteristics of immigrants_-gender, age, education, German proficiency, and nation of origin — in list form. The authors surveyed a sample of Swiss voters embedding the characteristics in paired and unpaired conjoint experiments and vignette experiments. The results found that the unpaired vignette, as used in our study, performed remarkably well, although it was not as accurate as paired vignettes or (un)paired conjoint experiments. Because the real-world decision mimicked a conjoint experiment, a striking result was that vignettes - which used hypothetical narratives, rather than the list form of the conjoint experiment-predicted behavior in the real-world. What the study does not tell us is how the two methods would perform when the decision-making process does not parallel the structure of a conjoint experiment, which may be better captured by narratives rather than lists. We suspect that a carefully constructed factorial survey experiment would outperform the conjoint experiment. 


\section{Appendix B}

Strength of Causal Inference and Sensitivity Analysis

\section{A. Strength of Causal Inference for Model Parameters}

Our randomized factorial design implies that the parameters of our model vary in how close they approximate causal effects. The most important parameters of our model are the total effects of vignette characteristics on likelihood to success $\gamma$ (eq. 5) and intention to protest $\pi=\gamma \beta+\phi$ (eq. 9). Our design affects the properties of estimates of $\gamma$ and $\pi$ : because we randomly assigned levels of vignette dimensions to vignettes, we can safely assume that our explanatory variables (i.e., vignette characteristics) $X_{i j}$ are orthogonal to each other (increasing statistical power of tests of $\gamma$ and $\pi$ by reducing multicollinearity) and to the disturbance term $\delta_{i j}$ (reducing bias in estimates of $\gamma$ and $\pi$ ) (see Figure 3). Moreover, because we also randomly assigned vignettes to individuals we can safely assume that $X_{i j}$ are orthogonal to $\alpha_{j}^{M *}$ (eq. 5) and orthogonal to $\alpha_{j}^{T}$, which increases efficiency of estimates of $\gamma$ and $\pi$ (eq. 9). These design features eliminate bias due to the effects observed and unobserved variables (or heterogeneity) across individuals, including self-selection bias. This implies that we can interpret $\gamma$ and $\pi$ as causal effects under relatively weak assumptions. $^{24}$

\footnotetext{
${ }^{24}$ Because each respondent assessed success and protest intentions for each of the ten vignettes, they provide outcome information for multiple levels of each vignette dimension. If we consider vignette dimensions as randomized "treatments," it follows that we can estimate, under weak assumptions, counterfactuals: How would a subject respond if they were in the "control" group? In other words, we can estimate unit causal effects for an individual. Then, by averaging across individuals, we can obtain the average treatment effect (Morgan and Winship 2015). These assumptions are temporal stability (that the timing of exposure to treatment and control is irrelevant) and causal transience (that prior exposure to the treatment and control is irrelevant) (Holland 1988). We tested both of these assumptions by interacting each vignette dimension with dummy variables for vignette number. Familywise tests yielded statistical support for the assumptions.
} 
This does not hold for the structural form for intention to protest (eq. 7). Because $M_{i j}^{*}$ was not randomly assigned, but instead is an endogenous regressor, $M_{i j}^{*}$ could conceivably be correlated with $\varepsilon_{i j}$. Here, we must assume conditional independence: $\varepsilon_{i j}$ is orthogonal to $M_{i j}^{*}$ after controlling for $X_{i j}$ (Figure 3). Because this is a within-individual model (level-1 on hierarchical linear model terms), we are controlling for unobserved stable characteristics that vary across individuals, but not characteristics that vary between vignettes. Therefore, $\beta$ and $\phi$ are within-person effects, but not causal effects (in the sense of $\gamma$ and $\pi$ ) because $M_{i j}^{*}$ is neither manipulated nor randomized. Bias would arise under reverse causality—if $Y_{i j}^{*}$ feeds back on $M_{i j}^{*}$ - or if a potential confounder that covaried with the (temporal) process of assessing vignettes was also correlated with success $M_{i j}^{*}$ and intention to protest $Y_{i j}^{*} \cdot{ }^{25}$ In other words, the reducedform (total) effects $(\gamma \beta+\phi)$ of $X_{i j}$ are causal effects, but the separated direct $(\phi)$ and indirect effects $(\gamma \beta)$ are not causal and, instead, should be interpreted as within-individual conditional associations (see Holland 1988; Sobel 2008; Matsueda 2012 for a discussion of these issues).

Unlike our first-level equations, eqs. (10) and (11) neither identify causal effects nor completely control for unobserved heterogeneity across individuals. Therefore, we must rely on the assumption, typically made in observational research, that the disturbance terms are uncorrelated with covariates in question once we include key control variables in the model. Since this is a strong assumption, we interpret individual-level coefficients as conditional associations and not as causal effects.

B. Sensitivity Analysis: Robustness of Tobit Models

\footnotetext{
${ }^{25}$ A potential solution to this endogeneity problem would require an instrumental variable: a randomized vignette characteristic that affects success but does not influence intentions while controlling for success.
} 
Because our probability scales of likelihood of success and protest intent are bounded by 0 and 100, and reveal nontrivial clumping at the lower limit of 0 , we estimate a censored regression or Tobit model. Figure B1 shows the distributions of our two endogenous variables. The shapes of the distributions are typical for survey items measured on a probability scale. Our variable, intention to protest appears clearly censored from above and below, while likelihood of success appears censored from below. Tobit models correct for censoring, but also make additional assumptions about the data, which if violated, can result in biased and inconsistent estimates (Greene 2003). Therefore, we examined the robustness of the model's estimates to violations of assumptions.

\section{[Figure B1 about here]}

First, the Tobit model assumes that the process producing censoring is identical to that producing the mean outcome. This assumption implies a proportionality constraint on coefficients of Cragg's (1971) specification of a probit model of censoring and a truncated regression model of the mean outcome (Greene 2003, p. 770). We use a likelihood ratio test of this constraint and reject the Tobit constraint for both success $\left(\chi^{2}(19)=122.19 ; p<.001\right)$ and intent $\left(\chi^{2}(19)=75.45 ; p<.001\right)$. This is a very powerful test, given our large sample size $(2,185)$. Comparison of the Tobit and truncated regression coefficients suggests identical substantive results, with the truncated regression coefficients uniformly slightly larger than the Tobit coefficients. Thus, we are reporting slightly conservative estimates.

Second, if errors are not normally distributed, estimates from the Tobit model will be biased and inconsistent. We used Chesher and Irish’s (1987) generalized residuals test (which yielded the same results as Pagan and Vella's (1989) conditional moment test) of normality in the Tobit model. The test rejects the null hypothesis of normality for both success $\left(\chi^{2}(2)=\right.$ 
25.38; $p<.001)$ and intention $\left(\chi^{2}(2)=46.31 ; p<.001\right)$. Therefore, we followed Greene’s (2003) strategy for estimating a Tobit model with non-normal disturbances by transforming the dependent variable and estimating a survival model, which has the identical likelihood function as the Tobit model with censoring from below (where our censoring is acute), under alternate specifications of the disturbance distributions (normal, logistic, Weibull, and gamma). We found the gamma distribution fit success best but the normal fit best for intention. Moreover, the substantive results remained unaltered, regardless of which distribution was fit.

Finally, if the assumption of a homoskedastic error term is violated, estimates of coefficients can be biased and inconsistent. To address this issue, we estimated a general heteroscedastic Tobit model, in which $\sigma_{i}^{2}=\sigma^{2} e^{\alpha^{\prime} w_{i}}$, and used a likelihood ratio test of the null hypothesis of homoscedasticity ( $\alpha=0$ ) (see Greene 2003, p. 769). Although the heteroskedasticity terms are modest in size, the joint test rejects homoscedasticity for success $\left(\chi^{2}\right.$ $(18)=59.91 ; p<.001)$ and intent $\left(\chi^{2}(18)=43.16 ; p<.001\right)$. The coefficient estimates of the heteroskedasticity model, however, were virtually identical to our reported results, leaving our substantive conclusions unchanged. We do, however, use the more conservative robust standard errors corrected for slight heteroskedasticity. 


\section{Appendix C}

Predictive Validity of Intention to Protest

Our theory of political protest explains intention to protest, which should be a key predictor of actual protest behavior. As noted above, we assume that actual protest behavior results from a willingness to participate, opportunity to contribute, and knowledge of the opportunity (Klandermans 1984, 1997). This implies that willingness will explain substantial variation in protest behavior when (1) opportunities and knowledge are important but vary slightly in the population at risk of protesting, or when (2) opportunities and knowledge vary substantially in the population at risk of protesting but are unimportant. By contrast, our model may be correct, but willingness explains modest variation in protest behavior because opportunities and knowledge are both important and highly variable in the population. With these possibilities in mind, we conducted a follow-up study six months later to determine whether intention to protest predicts actual protest behavior in the future.

We administered our follow-up survey to 196 respondents, with 130 respondents participating (a response rate of 66\%). Each participant received \$10 for completing the webbased follow-up, which consisted of nine self-report survey items about political participation drawn from the General Social Survey and the World Values Survey. We created two variables. First, a binary index, political action, of whether a respondent—during the last six months—-had written a letter expressing a point of view to an editor or a politician; signed a protest letter or petition; hung a political poster or sign on a wall; painted a political slogan on a wall; joined a social or political advocacy group; attended a meeting or rally about politics; participated in a demonstration or protest march; taken part in a job action or strike. Second, a binary variable, protest behavior, of whether a respondent had participated in a demonstration or protest march. 
To predict the probability of future political action and protest behavior, we estimated predicted values of intention to protest under various scenarios for each of our respondents. We hypothesize that if our models of intention to protest has predictive validity, then predicted values of intention to protest will correlate with self-reports of actual protests and political actions administered six months later.

We use logit models to predict the probability of participating in any form of political action as well as demonstrations and protests. We find that predicted values of intention to participate are significantly associated with actual protest behavior. ${ }^{26} \mathrm{~A}$ ten-point increase in predicted intentions to protest is associated with a .22 increase in the odds of reporting any political action. Likewise, a ten-point increase in predicted intentions to protest is associated with a .30 increase in the odds of reporting participation in a demonstration or protest six months later. These estimates are best interpreted as a lower bound given that (1) the situations depicted in our vignettes depart from the real situations confronted by students in the next six months, (2) our measure of political behavior is heterogeneous, and (3) we theoretically expect opportunities and knowledge of opportunities (not captured by our vignettes) in the real world to be important. Therefore, these results suggest predictive validity for our measure of intention to protest.

\footnotetext{
${ }^{26}$ We estimated negative binomial models predicting the count of political action and protest behavior. We found similar results as the logit models (results available upon request).
} 
Table A1. Dimensions and Levels of the Student Protest Factorial Survey

\begin{tabular}{ll}
\hline Dimensions & Levels \\
\hline Collective good & (1) The proposed tuition hike will amount to a $1 \%$ increase in the tuition you will pay. \\
(2) The proposed tuition hike will amount to a $10 \%$ increase in the tuition you will pay. \\
(3) The proposed tuition hike will amount to a $50 \%$ increase in the tuition you will pay. \\
(4) The proposed tuition hike will amount to a $100 \%$ increase in the tuition you will pay.
\end{tabular}

Selective punishments (1) The University states that it will not penalize students who participate in the walk-out.

(2) The University threatens that students who participate in the walk-out will receive incomplete grades in their courses and will have to make up missed work within one week.

(3) The University threatens that students who participate in the walk-out will receive failing grades in their courses.

(4) The University threatens that students who participate in the walk-out will be subject to expulsion.

Selective rewards

(1) Blank

(2) A national student federation will provide a \$10 debit card to every student who participates in the walk-out.

(3) A national student federation will provide a \$50 debit card to every student who participates in the walk-out.

(4) A national student federation will provide a \$200 debit card to every student who participates in the walk-out.

Social inducement $\quad$ (1) You have not been approached by anyone to participate in the walk-out.

(2) A few days before the walk-out, an acquaintance approaches you and urges you to participate in the walk-out with them.

(3) A few days before the walk-out, one of your friends approaches you and urges you to participate in the walk-out with them.

(4) A few days before the walk-out, three of your friends approach you and urges you to participate in the walk-out with them.

Reputational incentives (1) Blank

(2) In conversing with your friends and family, the clear consensus among them is that they will admire anyone who takes part in the walkout.

Solidarity frame

(1) Blank

(2) In the days before the walk-out is to begin, the student group declares that all students should unite behind the walk-out as solidarity is the only defense against social injustice.

Efficacy frame

(1) You do not know how student walk-outs have affected tuition hikes at other American universities.

(2) The student group provides information that walk-outs comparable to the one being planned have stopped tuition hikes at other American universities.

Injustice frame

(1) The University's president and top administrators have announced that they are not going to adjust their salaries for the coming year. 
(2) The student group reveals that the University's president and top administrators are planning a $10 \%$ increase in their salaries for the coming year.

(1) In the morning on the first day of the walk-out, you learn that no students (or $0 \%$ of 28,000 possible students) have participated in the walk-out.

(2) In the morning on the first day of the walk-out, you learn that one student (or $0.0036 \%$ of 28,000 possible students) has participated in the walk-out.

(3) In the morning on the first day of the walk-out, you learn that five students (or $0.018 \%$ of 28,000 possible students) have participated in the walk-out.

(4) In the morning on the first day of the walk-out, you learn that twenty students (or $0.07 \%$ of 28,000 possible students) have participated in the walk-out.

(5) In the morning on the first day of the walk-out, you learn that one hundred students (or $0.36 \%$ of 28,000 possible students) have participated in the walk-out.

(6) In the morning on the first day of the walk-out, you learn that two hundred and fifty students (or $0.9 \%$ of 28,000 possible students) have participated in the walk-out.

(7) In the morning on the first day of the walk-out, you learn that five hundred students (or 1.7\% of 28,000 possible students) have participated in the walk-out.

(8) In the morning on the first day of the walk-out, you learn that one thousand students (or 3.6\% of 28,000 possible students) have participated in the walk-out.

(9) In the morning on the first day of the walk-out, you learn that five thousand students (or 17.9\% of 28,000 possible students) have participated in the walk-out.

(10) In the morning on the first day of the walk-out, you learn that ten thousand students (or 35.7\% of 28,000 possible students) have participated in the walk-out.

(11) In the morning on the first day of the walk-out, you learn that twenty thousand students (or $71.4 \%$ of 28,000 possible students) have participated in the walk-out.

(12) In the morning on the first day of the walk-out, you learn that twenty-five thousand students (or $89.3 \%$ of 28,000 possible students) have participated in the walk-out.

Note: 'Blank' indicates that a level for a particular dimension was not mentioned in a vignette. 

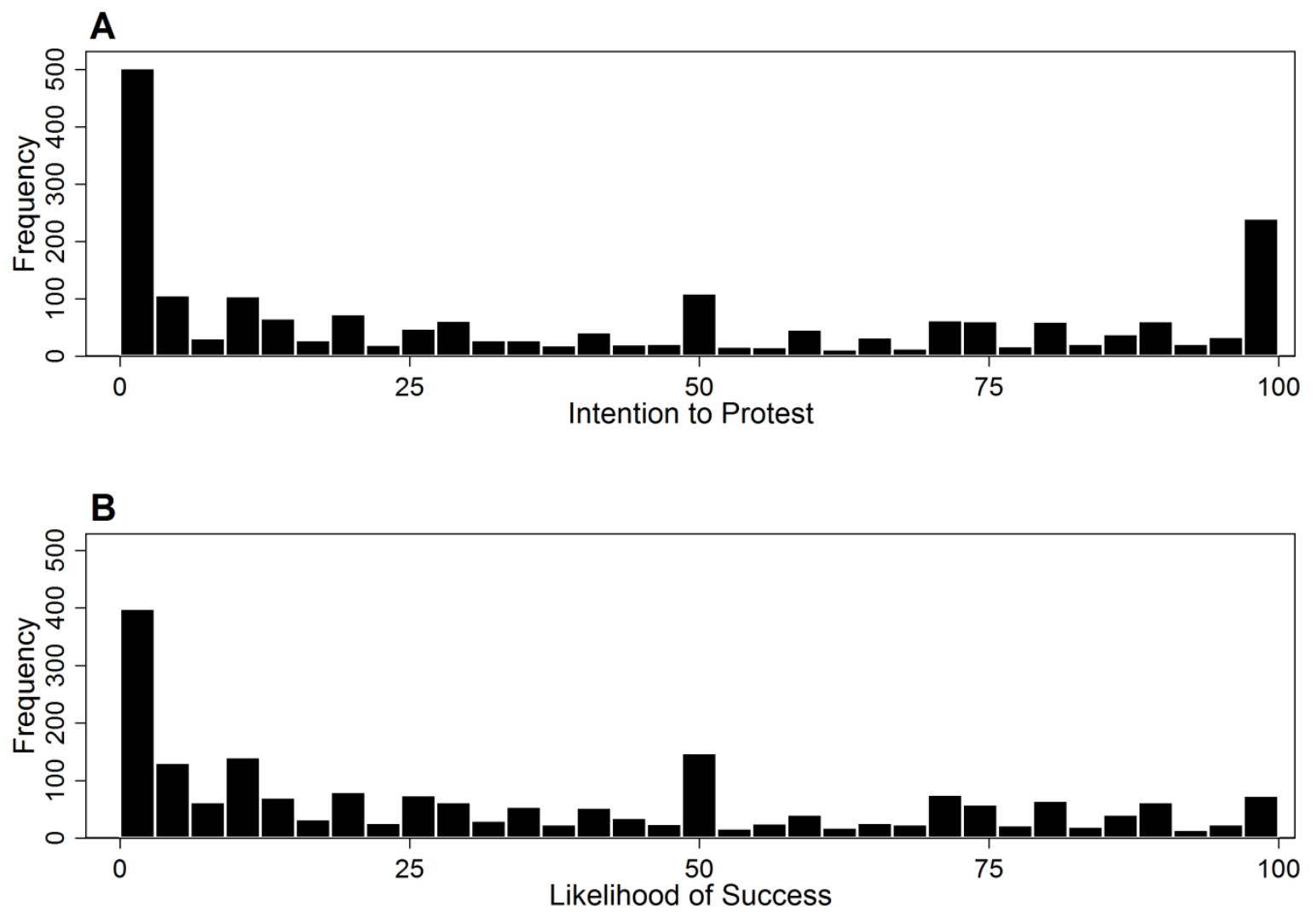

Figure B1. Histograms of Intention to Protest (Panel A) and Likelihood of Success (Panel B). 